University of Louisville

ThinkIR: The University of Louisville's Institutional Repository

Electronic Theses and Dissertations

6-1946

\title{
The opportunity class of the Mary D. Hill School.
}

Gladys E. Wyatt

University of Louisville

Follow this and additional works at: https://ir.library.louisville.edu/etd

Part of the Education Commons

\section{Recommended Citation}

Wyatt, Gladys E., "The opportunity class of the Mary D. Hill School." (1946). Electronic Theses and Dissertations. Paper 2192.

https://doi.org/10.18297/etd/2192

This Master's Thesis is brought to you for free and open access by ThinkIR: The University of Louisville's Institutional Repository. It has been accepted for inclusion in Electronic Theses and Dissertations by an authorized administrator of ThinkIR: The University of Louisville's Institutional Repository. This title appears here courtesy of the author, who has retained all other copyrights. For more information, please contact thinkir@louisville.edu. 


\title{
UNIVERSITY OF LOUISVILLE
}

\author{
The Opportunity Class \\ of the Mary D. Hill School
}

\begin{abstract}
A Dissertation
Submitted to the Faculty

of the Graduate School of the Univergity of Louisville

In Partial Fulfillment of the

Requirements for the Degree

of Master of Arts
\end{abstract}

Department of Education

by

Gladys E. Wyatt

Year

1946 
NAME OF STUDENT: Gladys E. Wyatt

TITLE OF THESIS: The Opportunity Class

of the Mary D. Hill School

APPROVED BY READING COMITTEE COMPOSED OF THE FOLLOWING MEMBERS:

Mary E. Burton

Hilda Threlkeld

NAME OF DIRECTOR:

J. J. Oppenheimer

DATE: Yume 8,1946 
THE OPPORTUNITY CLASS

OF THE MARY D. HILL SCHOOL 
Table of Contents

Chapter

Page

The Introduction $\ldots+-\ldots+\ldots$

I The Development of the opportunity Class at the Mary D. Hill School The original Plan - - - - - - The New Venture - - - - - - - Re-Testing and Re-Grouping $\overline{-}--\ldots-\ldots-\ldots$

II The Survey of the literature

Views on the Individualization of Activities 35 Hethods Used the Last Twenty-five Years Experimental Schools Reports $------\cdots-$ Conclusions $-\ldots-\ldots-\cdots$

III The Teaching of Remedial Reading in the Mary D. Hill Opportunity Class $\ldots+\ldots$ The Importance of Reading

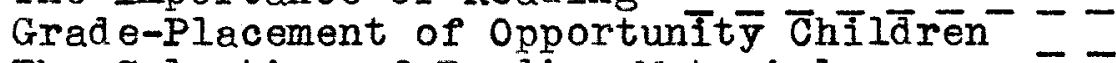
The Selection of Reading Material

A Typical Day in an opportunity Classs - -

A Typical Lesson Plan $-----\overline{-}$

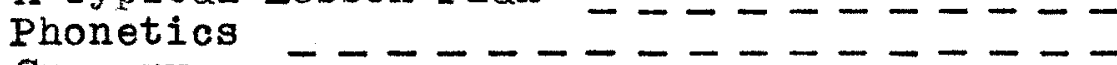
Surmary

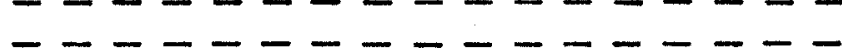

IV A Statistical Analysis of Reading of the Opportunity Class

V The Evaluation

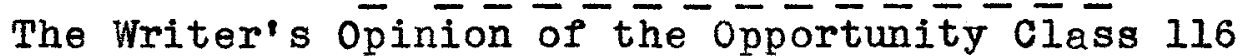

The Value of a Coach Class from an Administrative Point-of-View

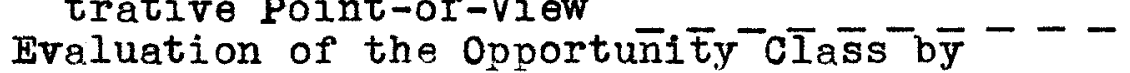
on-the-Spot-observers

Letters from Parents - - - - - - - 128

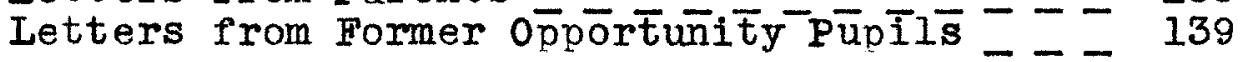

Summary 


\section{List of Tables}

Table

Page

I Records Taken From Charts Kept in Classroom 100 from 1936 to 1945

II Number of Children (Boys and G1rls) Selected 102 for the Opportunity Class, 1936 to 1945

III Comparison of Five Reading Groups in the Opportunity Class Coached from September, 1945 to January, 1946

IV Range of Gain in Months During the Training Period from September, 1945 to January, 1946

$\nabla \quad$ Number of Cases Making Accelerated, Normal and Retarded Progress or No Progress from September, 1945 to January, 1946 
List of Figures

Figure

I Reading Progress in Months Made by 43

Children Who Spent Five Months in the Opportunity Class

II Reading Progress in Months Made by 19 Chilaren Who Spent Eight Months in the Opportunity Class

III Reading Progress in Months Made by 55 Children Who Spent Nine Months in the Opportunity Class

IV Reading Progress in Months Made by 29 Children Who Spent Eighteen Months in the Opportunity Class

$\mathrm{V}$ Reading Progress in Months Made by 14

Children Who Spent Twenty-seven Months in the Opportunity Class

VI Percent of Pupils Who Gained or Lost in the Opportunity Class

VII Actual Number of New Children Selected Each Year for the Opportunity Class

VIII Distribution of 41 Cases According to 104 Gray's Oral Test Scores, September, 1945

IX Distribution of 41 Cases According to Gray's Oral. Test Scores, January, 1946

$x$ Individual Case Records for Five Months from September, 1945 to January, 1946, Showing Gains and Losses According to Gates Oral Reading Paragraphs

XI Chronological Age Distribution of 41 Cases in September, 1945

XII Mental Age Distribution of 41 Cases in September, 1945 
List of Figures

\section{Figure}

XIII Actual Grade-Placement Distribution of 109 41 Cases from September, 1945 to January, 1946

XIV Reading Grade-Placement Distribution of 41 Cases Tested in September, 1945

XV Reading Grade-Placement Distribution of 41 Cases Tested in January, 1946

XVI Actual Grade-Placement Distribution of 41 Cases in January, 1946 
INTRODUCTION 


\section{INTRODUCTION}

In almost every classroom in the country there are overage boys and girls, retarded children who have been pushed along through school after repeated fallures have convinced both them and their teachers and companions that they are of little consequence. Since not much can be done to remedy the situation after so many years, the only solution in most cases is to pass the children along as rapidy as possible, allowing them to sit in the successive grades where the intellectual tasks are completely beyond their limited abilities. Here they acquire more bad habits and often become personality or behavior problems.

Yet these slow children are not being educated. They are Americans and education is for all the children of all the people. They are the Americans who are our future citizens, who will grow up and take their places in the world, will make homes, raise families, and cast votes. "What they become, the ideals they develop, are vital to our national welfare."

It is said that these slow children are the ones who "clog the machinery of public education". They take up

W. B. Featherstone, Teaching the Slow Learner, In Editor's Introduction by Hollis L. Caswell. p. V. 2 Loc. cit. 
the teachers' time and energy which more profitably could be devoted to the brighter students. Their repeated failures cost the schools much of the tax-payers' funds which could be allocated to more promising pupils.

And yet, if these unfortunate children are to share alike with all other children in their heritage of American democracy, the school programs will have to be remodelled or adjusted to fit the schools to their needs. Slow learners can be taught because teachers have learned to study the individual and to diagnose cases for individual adjustment. Educators have begun to realize that their school situations should hande the slow learner as well as the rapid learner.

Dr. Judd, of Georgetown College, Kentucky, says, "Every child should succeed in something. Now, let us lay down a principle which is indispensable in the teaching process. All work should be brought down to the level of the child so that he might have the opportunity to achieve some successes. This goes for persons on any level, from the kindergarten through the graduate level. It is as necessary as the air we breathe."

It was this same conviction that prompted the principal

Romie Dustin Judd, "Psychologize Your Teaching," Kentucky School Journal, 24: (November, 1945), p.22. 
of the Mary D. Hill School to make plans for the formation of an ungraded class. When she first came to the school, the retardation among the children of the fourth, fifth and sixth grades was appalling. Large overaged boys were sitting in oversized desks in the back of the rooms, doing nothing, learning nothing. The teachers were helpless in facing this problem of teaching children with no scholastic levels. As long as they behaved themselves, the children were tolerated. More often than not, they became problem cases, were expelled or transferred to a special school for bad boys. The Neighborhood

The Mary D. Hill School is located in the central part of the city, on the southeast corner of Sixth and Kentucky Streets, Louisville, Kentucky. Its 350 children come from the district bounded on the north by York Street, on the east by Third Street, on the south by Ormsby Avenue, and on the west by Twelth Street. This area includes many downtown hotels, apartment hotels, rooming houses, some homes of good, sturdy, middle-class people, and many homes of very low economic status.

The school population has been very transient, especially during the war years when children stayed in one school only three or four weeks at a time. Children living in trailers parked in auto lots came to school during spring 
racing meetings or religious revivals in which their parents took part. This moving from school to school and from city to city is an important factor contributing to children's retardation. This spotty attendance with the serious non-attendance of the country children who move to town, is very disturbing. Large overage boys and girls are almost beginners scholastically because they "lived too far from the nearest school", or "the bridges were down and we couldn't ford the streams," or "we had to help put in the crop". They have grown up without schools and feel no need for them now. Their parents are 1gnorant and uninterested in education or school attendance and often must be forced by the courts to keep their children in school.

Then there are the children retarded by physical defects, and illness who are financially pronounced well enough to begin again the long uphill pull to an education against heavy odds, among strangers, in new and unwelcome surroundings. "A teacher who has one or two such children on her class faces a difficult problem. Logically she should be instructing these children in beginning reading, yet the curriculum of these grades is designed for normal children who can read."

White House Conference on Special Education, Child Care and Protection, Sec. III, p. 21. 
Finally, there are the naturally slow learners who are found in every school. "Most mentally retarded children in the United States are not trained in institutions or in special classes, but in the regular classes. Whether or not this procedure is advisable, is, of course, dependent upon the organization of the regular grades." These children selected from the regular enrollment at Hill School plus the special cases from other Louisville schools, make up the membership of the Opportunity class.

The problem chosen for this thesis is an attempt to describe the steps taken in the formation of an ungraded class at the Mary D. Hill School, its function, its growth and expansion until its service was introduced to the whole school in co-operation with the regular program of the grades. Its name was changed to the Opportunity class of the Mary D. Hill School; its enrollment was planned to include children from all parts of the city, and its instruction was to be strictly remedial.

Although the class has served for years, the realization that comparatively few people fully understand its function prompted this study. Other schools may be considering the formation of similar classes and may appreoiate, and benefit by, the study which shows the origin, the development, and the improvement through the years. 
Since schools are constantly on the lookout for new ideas or programs to give them greater efficiency, a study of this kind should prove interesting and valuable. A survey of the literature on experimental schools, work with slow-learning pupils, special classification and types of activity for dull-normal children, indicates that "the education these slow-learning children require is of major importance to American democracy, ${ }^{6}$ and that many educational workers are "concerned with the better education of the less fortunately endowed of our children."

Chapter I will deal with a description of the development of the Opportunity Class at the Mary D. Hill School, and a brief resume of the literature covering the different fields of corrective and remedial instruction will be given in Chapter II of this study.

W. B. Featherstone, op.cit., p. III in Editor's Introduction.

7

Ibid., p. IV. 


\section{CHAPTER I}

THE DEVELOPMENT OF THE OPPORTUNITY CLASS

AT THE MARY D. HILI SCHOOL 


\section{CHAPTER I \\ THE DEVELOPMENT OF THE OPPORTONITY CLASS \\ AT THE MARY D. HILI SCHOOL}

In this chapter an attempt will be made to present briefly the development of the Opportunity Class at the Mary D. Hill School, at Sixth and Kentucky Streets, in Louisville, Kentucky. This class was begun as a ploneering project to meet the school's own situation, to meet a problem of retardation which had interested the principal and teachers of the Hill School over a period of years. The principal, Miss Agnes B. Dickson, had taken an active interest in each child in her school and was conscious of his individual problems. She agreed with Margaret Leckie who says, "Children are individuals. No teacher needs to be told that there are as many individual learning problems in a room as there are pupils. Some pupils come to our rooms with a fine learning attitude, with their interest self-aroused, and with minds receptive to the things we have to give them. We will find in any classroom a wide variation in meaningful background of ideas, a broad difference in the emotional development of the various individuals; and mental and physical vigor of a high type or mental and physical capacity of a limited type. There is no denying that these differences exist. The question before us is, 
-What can or should we do about them?" ${ }^{8}$ The principal also believed that the purpose of our teaching should be to bring out the best effort of each individual pupil that he may "grow in harmony with his ability, interests, present needs, and probable future needs".

In 1928 she began to consider the problem of retardation in earnest. She consulted the superintendents, school principals and teachers as to how the problem was being met in other situations, how and why certain methods could or could not be used in her particular school, what steps she could take, as an individual, toward the solution of the problem. The answer to the question seemed to be the formation of a group or class in her school where retarded pupils could be given individual attention and study. After consultations with Dr. A. A. Rubado, the superintendent of elementary education of the Louisville Public Schools, plans were made to form such a class, and the principal and the writer on the morning of January 4, 1930, began the process of selecting members of the first enrollment. Around a nucleus of four overage boys, a class of twenty problem children, boys and girls, was selected with the help of the fourth, fifth, and sixth grade teachers.

\footnotetext{
8

Margaret Leckie, Provisions for Individual Differences, Teachers' Service Bulletin in Reading, p. I, April, 1943.

9 Ibid., p. 2.
} 
The first four boys were taken from the fourth and fifth grades where, as nonreaders, they were being allowed to sit as long as they behaved themselves or until they reached the legal age for quitting school. They were of fairly low mentality and had been passed from grade to grade with no levels of accomplishment. Since "every child, not an institutional case should be educated to the extent of his ability", "the teacher was anxious to find out just how much these boys and girls could accomplish. A brief survey of the histories and environment of the children revealed interesting factors which may have contributed to their retardation.

The twenty members of the class were divided into groups for instruction in reading, arithmetic, spelling and writing. These subjects were not taught systematically in accordance with any textbooks or courses of study. In the main, the pupils were engaged in a series of projects or enterprises believed by the teacher working with them to be of value. These skills were taught as they were needed, in groups, if possible, or individually, in ways which seemed to be serviceable to slow-learners. The most emphasis, however, was placed on reading, and noticeable gains were made by

10

Agnes B. Dickson, History of the Opportunity Class of the Mary D. Hill School, Report to Dr. Long, p.I, April 14, 1937, (Unpublished) 
boys who began at the primer and pre-primer levels.

To stimulate interest, the teacher often tead to the class. Sometimes she would start reading a story and let one of the groups finish it. Among the books read to the class, for listening pleasure only, were Tom Sawyer, Huckleberry Finn, Doctor Dolittle, and Pinocchio. One of the members of that first class, now a corporal in the army, paid the school a visit and spent quite a long time with his former coach teacher. While reminiscing, he said, "Of all the things that I remember about your class, your reading of Huckleberry Finn impressed me most. I used to dream about him at night. Then I couldn't wiat to get to school to find out what had really happened to him!" "It would be a great injustice to assume that because a pupil is slow in reading, he is necessarily slow in all other things. - artistic skill and competence with one's hands are just as much the concern of the school as reading or arithmetic." ${ }^{11}$ Therefore, much handwork was planned for this group and some commendable drawings, woodwork, and paper construction work resulted. Rock garden contests and better homes contests were entered and the boys won many ribbons because of their mechanical and artistic abilities. Some of the children acquired skills in the use of their hands which helped them obtain employment after they left.

11

W. B. Featherstone, op.cit., p. 3. 
But "it is very deadening to a child to spend his entire time, year after year, with a low homogeneous group, ${ }^{12}$ and the principal conceived "idea of giving the children a more varied program and the privilege of living in a normal group if only for a game at recess. Ungraded classes, as a whole, tend to stunt a child." ${ }^{13}$ He should be given a chance to move about among his fellows because "no human being should ever be set apart." ${ }^{14}$ Throughout life children of different abilities should live and grow together; should help each other and learn from one another. Instead of its being used as a class for branded children and set apart from the others, it was decided that its use should be extended to meet the needs of the whole school and its opportunities and privileges should be given to a greater number of children. At the same time the regular members of the class could be placed in normal groups where they would enjoy the association of children of their own age and achievement.

\section{The New Venture}

After a few terms of the original procedure, the new policy was adopted, a testing program was instituted, (this

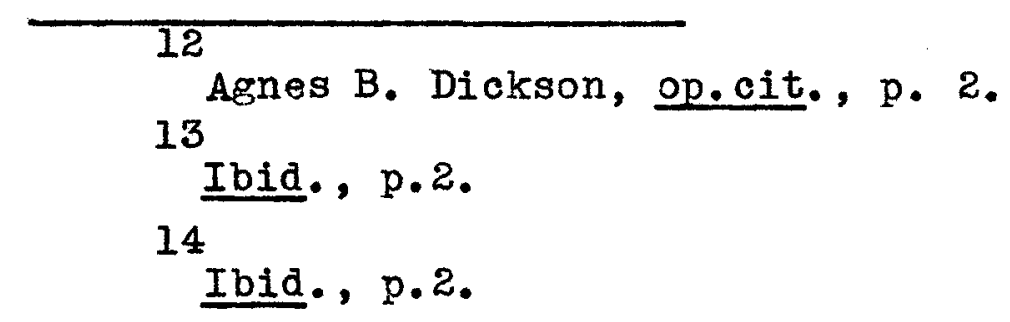


program will be explained fully in Chapter 3), new pupils from all grades were considered as candidates and the new venture was introduced on October 1, 1936.

Since the greatest retardation had been in reading, a special reading room for coaching was the natural solution. Most teachers manage to accommodate children in other subjects; reading, however, complicates the situation where too many groupings are necessary. They agree that it is an impossibility for one teacher at one time to be conscious of each pupil as an individual in a room of thirty or forty pupils. With large classes in a regular school situation, the teachers do not have time to provide individual reading for all of the different levels in the class. In a small class or group, each child can be given individual instruction. But in a regular class, the teacher has a course of study to follow, and she is allotted time to cover the required work. The curriculum of these grades is designed for normal children who can read. Many teachers set aside a part of the day, a special help period, to aid individual children with their work, to give them remedial instruction. An advanced pugil in the class is often helpful to a retarded child if the teacher cannot take time from the class duties to devote her attention to a backward child. Other teachers, however, say that the only solution is to consider the group as a whole, give work that approxi- 
mates the average needs, and to trust that the slower pupils w1ll approach the group standard.

"Schools should not require that mentally retarded children keep up with the curriculum constructed for normal children, but should have a curriculum adapted to his needs and capabilities." 15 Non-readers require adequate individual instruction. Therefore, with a re-organization of the regular grades in the Mary D. Hill School, the coaching program was begun.

Now, after eight years the program continues to run smoothly and the children conform to the natural situation in which they find themselves. They come and go from room to room on their own time, "have a sense of responsibility and appreciate the fact that they are allowed the freedom of passing through the halls from room to coach room with out policing." 16 Instead of a feeling of retardation there is one of success no matter how small the step forward may be. Some children of very limited ability at flrst learn to appreciate only the social contacts of their own mentalage group. They develop a feeling of importance because they have been noticed.

Years of bad habits have to be overcome, and there is 15 White House Conference on Special Education, Child Care and Protection, Sec.III, p.21. 16

Agnes B. Dickson, op.cit., p.3. 
often gery little foundation upon which to work. The teacher "goes to rock bottom before she can find anything to work with, because it is almost impossible to find the feeble ability." ${ }^{17}$ No matter how small the achievement, the child has the feeling of success and is interested in it. Often he has been the object of many jokes and cruel remarks concerning his retardation. The teacher must develop what skills he may possess, change his trend of thinking, reshape his outlook toward his education, and give him a feeling that he can learn. She must realize that it is a long uphill pull to teach slow-learning pupils how to read effectively; she must never lose patience and understanding: she must never lose sight of why the child cannot learn to read rapidy; she must not expect him to do better reading than his mental age would indicate.

The Mary D. Hill coach teacher has no particularly outstanding features in her methods of instruction. The entire idea is based on considering the child as an individual, a distinct personality. Because he is a certain age or in a particular grade does not mean that he can read at the grade level of that class. Children of all ages and from many grades meet day after day and read together. Never is there any ridicule, nor are comments made about age or ability.

17

Ibid., p. 3. 
In the coach room the teacher tries to make the lessons enjoyable and avolds giving any impression that the children are taking the special work as a punishment for poor reading. She is careful not to discourage them in any way, is most generous with praise, and furnishes opportunities for more successes than failures. She does not hesitate, however, to correct and caution when it appears that progress is being hampered by needless errors or unprepared assignments, especially when she knows improvement is possible.

At no time is a child pushed, nor is there any stress on achievement beyond the ability of the pupil. No concentrated work of any kind is done during the first year to increase his speed, particularly in reading. There are set up no definite reading standards. He is taught not to try to accomplish the impossible. He is not to worry about what the other children are doing, but is to try to better his own record, going ahead at his own speed.

The coach teacher makes an effort to identify the school's slow children before that become problems with established habits. "It is imperative that if reading correction is to serve its best purpose it should begin in the first grade. If this procedure is followed and the necessary assistance is supplied, we will not find pupils of high I.Q.'s who are still reading on fourth or fifth grade level in the eighth grade."

\footnotetext{
${ }^{18}$ May E. McCarthy, Teaching Reading to the Slow-Learner, p.2.
} 
Children like to come to the opporunity room because it is a very pleasant place. It is associated not only with feelings of success and achievement, but also with those of privacy and relaxation. The soft-green walls and the profusion of flowers and plants give the room an air of informality. The formal furniture, such as nailed-down desks, wall maps amd gloomy blackboards, have been removed. A large round library table surrounded by small chairs is placed in one corner of the room by a window and a small blackboard. The other furnishings consist of bookcases, one teacher's desk set between two large ferns near a window, a wicker couch, a spinning wheel, three low rockers, a large easel, a long table containing interesting objects like a model airplane, a Viking ship, a small globe of the world, new books, a hectograph machine, etc., two large rubber plants, and two smaller tables containing many potted plants. The old blackboards are painted dark green and serve as background for three or four pictures and a bulletin board where the test scores of the class are kept.

The relationship between the teacher and the child is informal and makes for greater ease in the classroom. The . pupil-to-pupil relationship is friendly and slightly-competitive, but loyal and cooperative in the child's own group. As the child begins to find hos place in school, evidences of insecurity and inadequacy, such as anti-social 
behavior, withdrawal from activities in the classroom, timidity, etc., may disappear for "nothing succeeds like success". If a program of varied activities, varied contributions, and varied levels of performance are "the normal and accepted state of affairs, ${ }^{19}$ most pupils will respond because of a feeling of "belongingness, a feeling of achievement and success".

Candidates for Enroliment in the Opportunity class

The enrollment of the Opportunity class is necessarily very small because of the over-crowded condition of the school. The Bureau of Research of the Board of Education has an ever-increasing list of possible candidates which could supply a large enrollment for the class; but it is felt that the needs of the Mary D. Hill School should be considered first. Therefore the class has accepted ohly a small number of these out-of-the-district candidates. All have been tested and investigated by the Bureau of Research before application for admission is made. Applicants are accepted on the basis of mental tests, normal behavior, and the degree of progress to be expected.

These special cases have been brought to the attention of the Bureau of Research by teachers who are puzzled by the

20 W. B. Featherstone, op.cit., p.100.

Ibid., p. 90 . 
lack of progress they make, or by anxious parents who realize that their children's school experiences are unsatisfactory. Mental ages and achievement are checked by the examiner through the use of tests, wuch as the Revised Stanford-Binet, the Detroit Word Recognition Test, the Metropolitan Readiness Test for Kindergarten and First Grade, and the Progressive Achievement Tests in Reading Comprehension. She recommends physical defect corrections before placement in any special class. If the case suggests remedial instruction such as is available at the Mary D. Hill School, she recommends placement in the Opportunity Class as soon as possible. This is ubject to the approval of the supervisor of elementary instruction, the principal of the Mary D. Hill School, and, of course, the parents of the child.

Candidates have come from private and public schools, from elementary and junior high school levels, and from other ungraded classes.

When a new candidate is recommended by the grade teachers of Hill School or by the Bureau of Research of the Louisville Public Schools, he is given a simple testing program at the Mary D. Hill School consisting of oral reading from standard21 ized tests and school readers, spelling, writing, and arithmetic

\section{1} pp. 1-2.

William S. Gray, Standardized Oral Reading Paragraphs, 
from the school's courses of study. If he is accepted as a member of the Opportunity Class, he is placed in the remedial reading group which his test score indicates as desirable. (This testing is explained in detail in chapter III.) If his other tests indicate various levels of achievement, an individual schedule is planned for him for which he is responsible. This schedule may be changed at any time during the term if his progress merits it.

His test results may place him in IA writing, $2 \mathrm{~A}$ spelling, $4 B$ arithmetic, and pre-primer reading. At given times or on bell signals (recess, lunch time, etc.), he leaves one room and takes up his work in another. Typical Individual Schedules

Mary J. entered Mary D. Hill School from out-of-town as a fourth grade pupil. She was placed in the opportunity Class and given the following schedule. 9:00 - 4B, Opening Exercises, Morning Work, etc., in 4th Grade 9:30- Remedial Reading, $2 \mathrm{~A}$ level in Opportunity Room. 10:15- 4B Play Recess. 10:45- 3A Arithmetic in 3rd Grade 11:45- Lunch 12:20- 2A Arithmetic in 2nd Grade 12:45- 3A Music, Language, Spelling in 3rd Grade. 1:30- 4B Art, Social Studies,etc., in 4th Grade.

\section{2}

Louisville Board of Education, Courses of study for Second, Third and Fourth Grades. 
After a month in $2 \mathrm{~A}$ arithmetic, she was promoted to $3 B$ and at promotion time in January, she was placed in $4 B$ for all work except reading which was on a $3 \mathrm{~A}$ level.

E.K., a private school pupil in the fourth grade, was found to have no achievement levels except in arithmetic on a $2 \mathrm{~A}$ level. His schedule takes him to five different teachers.

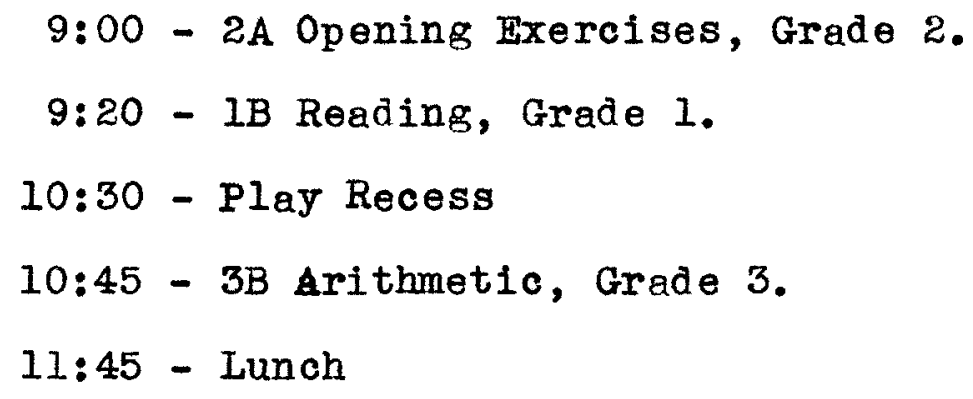

All of the teachers who are responsible for the children with individual schedules, hold conferences with the opportunity class teacher at promotion time. Progress is discussed, retention in the same grade or promotion is suggested and plans for each child's next semester are made.

These regular grade teachers who supervise the opportunity children's class work in their rooms are to be commended for the intelligent attitude and cooperative spirit demonstrated in the special care which must be taken in guiding the 
learning of these retarded children. Although they know that "slow-learning children learn, in general, by the same methods as brighter children," they realize that the activities of slow learners must be simpler, that the plans and objectives for them must be clear, specific and very concrete, that much drill and practice are needed in many learning skills like number combinations, pronunciation of words, language usage, and techniques of reading and writing. They know that slow-learning pupils need frequent assurance that their work is satisfactory, that they are progressing toward a definite goal. These teachers take a personal interest in each of the special cases in their classes where all pupils enjoy a wide variety of experiences in a normal situation.

Frequent evaluation of the slow-learners' work is necessary and the teachers keep accurate reports and suggest changes or reorganization of pupils' work at any time during the term. At promotion time all children doing satisfactory work are passed on to the next grade. Some of the slower ones, however, may need to be given further training toward "the goal of readiness" and will be retained in the same grades with the regular teachers for two or three terms.

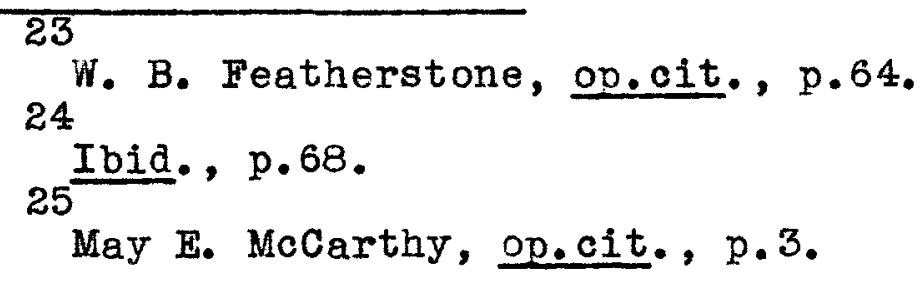


Often a child's retardation has been caused by illness or non-attendance in school. If he has a fair mentality his years of experience speed his work, the feeling of success comes fast, and he progresses rapidly. The teacher to whom he goes passes him along as quickly as possible. He keeps working at his own rate of accomplishment and, given the appropriate attention at the proper time and instruction to meet his needs, he builds up his levels, and often catches up with his own age-group in a very short time.

In order that the children may see their actual progress, a book with dally marks is left on the reading table; progress charts with contests between groups and test scores records are accessible to the children at all times. Treats and prizes for the winners help to stimulate interest and competition. This procedure together with the encouragement of the other teachers has made the coach room a pleasant place to which a child is privileged to go. Children who realize their own difficulties often come to the coach teacher and ask, "May I come up and read with you?" or "Do you have atplace for me in one of your groups?"

The class members are the nucleus of five or six reading groups to which are added Mary D. Hill ohildren from the first through the sixth grade, whose reading scores place them at one of the levels chosen for remedial instruction. Usually these children from the grades have little trouble 
with arithmetic and subjects not dependent upon reading; with the aid of remedial reading instruction, they progress from grade to grade as normal individuals who have been given the special privilege of attending the coach class. From 40 to 50 minutes a day are spent in definite reading instruction, either in groups or individually. Since the morning hours are considered best for young children's reading periods, the groups reading in primers, first and second readers are called before lunch. These periods are longer than those in the afternoon since beginners require more time for slow reading, slow thinking, much drill and practice. The children who are older both in age and experience, in the coaching program, come at the end of the day when the periods are from 30 to 45 minutes long. They also participate in reading activities in other grades in history, science, language, and geography, and make regular visits to the public library to do reading of both recreational and informational types.

In the six regular groups the levels usually range from the 0.0 or pre-primer level, through 4.0 and 4.5 which are fourth grade levels. The testing program, its procedure, and some treatment of phonics, etc., will be siven in Chapter III. For the first eight or ten weeks after the groups have been organized, they progress as units with the ability ratios remeining relatively constant. By this time, however, the 
teacher realizes that the poorer readers are tending to hold back the more alert children; or one or two in each group begin to show marked improvement and to surpass the efforts of their fellows. It is now necessary to re-adjust them to other groups, the top students of one group moving up to join students of a slightly higher group. If the lowest members of the lowest group do not advance, they seldom repeat a primer, but are given another on the same or a lower level. The selection of the pupils for the different groups is based on (1) the scores on Gray's Oral Reading Paragraphs, (2) the ability of the pupils in oral reading, and (3) the extent of participation in the lesson.

This general rearrangement or readjustment usually occurs three times a year and children who are mentally normal and have been retarded for some minor reason, like irregular attendance or frequent transfers from school to school, or physical defects which have been corrected, will find themselves in three or four groups during the year, having progressed rapidly from level to level after receiving intensive basic training in the mechanics and fundamentals which they have missed some where along the way. At the end of the first semester some doubtful cases are tested for placement in higher or lower groups. This year, 1945-46, however, for the purposes of this study a complete testing program of all 41 children who had been in regular attendance 
for five months, was conducted in order to obtain numerical results which have been tabulated in chapter IV.

In most cases there is no interruption in the routine at promotion time. A few individual schedules have to be modified or enlarged if the children have not been promoted in all subjects. (See Mary J.'s schedule on page 26.)

At the end of the school year each child is re-tested and his score recorded. If the score shows that his reading has been raised to the etandard for his present grade, he is returned to his normal class, to be cheaked the following year from time to time for signs of 10ss. In the event that he falls behind his class, he will be returned to the coach class for further strengthening. Also at this time of year new candidates recommended by the grade teachers are tested and tentatively grouped for the next semester.

The following September members of the lower level groups are retested for summer vacation loss. Often a 1.8 or 2.4 score in June will drop by September to 0.0 because of short memory span and a lack of encouragement and help at home. (See cases No. 211 and 236 on blue lines on Figure $X$ on page 105 of this study.) New pupils from out-of-toum districts are tested for correct placement in the grades. Most of these children are easily placed in normal classes and comparatively few are assigned to the Opportunity class. 
Regular reports are made to the Bureau of Research upon the progress of the special-case children. Often they are re-tested for achievement.

Points concerning the personnel of the class, the testing program, and its statistical treatment, opinions of educators, parents and former pupils, will be discussed in the following chapters. Some cormon errors with suitable remedial methods, type lessons, selection of reading material, et cetera, will also be described. 
CHAPTER II

THE SURVEY OF THE LITERATURE 
THE SURVEY OF THE LITERATURE

In a review of recent literature there is evidence that educators agree on the individualization of activities for pupils to promote growth in reading. There are widely different views, however, concerning the extent to which adjustment to individuals should be made. Some believe that reading activities and instruction should be based on the child's immediate day-to-day interests and should not be planned in advance. Others believe that all schooling should be planned systematically to prepare the child for adult life. Still othersbelieve "that the reading activities provided should be selected in the light of a clear understanding of the pupil's immediate and potential interests; his physical, social, mental, and emotional maturity; and the culture in which he lives... that needs vary as the culture changes."

There are also different views concerning the amount of individual instruction which is needed. In some schools, most activities are individualized according to the varying needs of the pupils. In other schools, provision is made for group and individual instruction. Both

\section{6}

William S. Gray, Adjusting Reading Programs to Individuals, No.52, Chapter I, October, 194I, p.5. 
views should be considered because there are advantages in both plans. In the writer's opinion, much depends upon the emotional nature, the mental ability, the level of maturity and the experience of the pupil. The results of research according to William S. Gray, indicate that "superiority attaches to no single pattern of adaptation." Results obtained by using all three plans are highly significant as to their merit.

"The children who can truly be called nonreaders will be found at the extreme end of the normal distribution and will constitute only a small percentage of the total school population." 28 Each case, however, presents a difficult problem and requires insight and understanding on the part of the classroom teacher who must employ individual techniques in the treatment of almost every nonreader. The method selected for teaching these children must meet the needs of the individual. If he fails under one method, an entirely new one must be substituted so that he will not develop the attitude of failure.

Experimental Methods.

Many methods have been introduced in the last twentyfive years with more or less success.

Ibid., p.4.

Ibid., (Mildred E. Sherwood), October,1941, p.300. 
29

James Hinshelwood was successful in teaching nonreaders whose difficulty he called "congenital word-blindness" by means of the old fashioned A-B-C method. Fernald and 30

Keller placed strong emphasis on the kinesthetic method by which troublesome words were taught by tracing and writing from memory, pronouncing the syllables as they were written.

\section{$\frac{\text { Directional }}{31}$ Training}

Orton claimed that reading disability was caused primarily by a tendency to reverse letters and words. Gates 32

and Bennett advocated special emphasis on directional training, the left-to-right progression along a line of reading. 33

Stanger and Donohue developed a method in which individual letters, combinations of letters, and sounds of letters were taught with words or pictures as illustrations. As

James Hinshelwood, Congenital Word-Blindness,

H. K. Lewis and Company, Ltd., 1917,p.301. 30

Grace M. Fernald and Helen Keller, "The Effect of Kinaesthetic Factors in the Development of Word Recognition in the Case of Non-Readers," Journal of Educational Research 4: December, 1921, pp. 355-377.

31

Samuel T. Orton, "Word Blindness in School Children," Archives of Neurology and Psychiatry, 14: November, 1925, pp. $518-615$. 32

Arthur I. Gates and Chester C. Bennett, Reversal Tendencies in Reading, 1933,pp.1-33.

Margaret A. Stranger and Ellen K. Donohue, Prediction and Prevention of Reading Difficulties, $1933, \mathrm{p} .30 \overline{3}$. 
soon as a few sounds were mastered, words using only these sounds were learned; then sentences and simple stories were introduced with emphasis on directional training.

Emphasis on Phonetic Training

Monroe developed a method of remedial reading in which the sounds of the consonants and vowels are taught. If the child experiences difficulty in discrimination of like and unlike sounds, tracing is used.

Dolch's method is similar to fonroe's in that he emphasizes phonetic training. He also believes in developing a basic sight vocabulary and the extensive reading of simple narrative material.

\section{The Cross-Motor Pattern.}

In the schools of today children learn to read whole words and phrases by the "look and say" method. Good vision and good visual memory are necessary or the method fails. Some children have difficulty in moving their eyes from left to right along the printed line. Their eye movements seem to skip back in the opposite direction. As a result words and symbols are read backwards.

34 35

Marion Monroe, Children Who Cannot Read, 1932, p.116-35. E. W. Dolch, "Mass Remedial Reading", Educational Administration and Supervision, 22:0ctober, 1937, pp.541-546. 
36

Margaret sttanger, psychologist and reading diagnostician of the Ethical Culture Schools, says that ten to fifteen percent of the children starting to school suffer from the handicaps known as cross-motor pattern. She says that "unless this condition is more universally recognized for what it is before faulty habits are formed, these children are not going to learn to read with the rest of their classmates."

Dr. Stella S. Center, director of the Reading clinic, New York University, to which children come from all parts of the United States, estimates that "approximately 25 percent of the children in each school grade from the first through high school fail to master reading skills as they should." At the reading clinic, "a diagnostic eye test is given each child. With an instrument known as a telebinocular, eyes are tested for fusion and refraction." With the use of simple pictures, toys, instruments such as the flashmeter or projection lantern, the tendency toward crossmotor pattern is discovered. The child is asked to reproduce the pictures, toys, words, or geometric patterns which he has seen. If he is left-handed mentally, very probably he will remember the object or pattern, but will turn its

David Taylor Marke, (Associated Press Writer), "Help for the Mental Left-Hander", Louisville Courier Journal, 182: Sec.2, October 23,1945, p. 2 . 37 Ibid., p.2. 
position completely around.

If the cross-motor pattern exists, remedial measures are taken. The alphabet is taught phonetically; the child learns to make each letter. "He sees it, hears it, feeis it vocally, feels it through his fingers." Many children have overcome their handicaps within six months.

Experiments and Studies

Many experiments and studies have been made to discover and correct the errors made by poor readers, to determine the relationship between physical defects and reading disability and behavior. The following paragraphs describe remedial plans and experiments which have been tried by schools, clinios, and school systems.

\section{The Speyer School Experiment}

The Speyer School, Public School 500 of New York City, was organized as an experimental school in February,1936. Its purpose was to try out new methods and materials and a new general curriculum for the instruction of slow-learning pupils. Regular textbook procedure was discarded in favor of"a series of projects or enterprises believed by the

38

Ibid. , p.2. 39

Ibid. , p.2. 
teachers and specialists working with them to be of " 40

intrinsic value," such as excursions to places of interest and the follow-up activities, construction of displays, large illustrations and exhibits. Less pressure was put on reading than at other New York schools; yet much remedial instruction was given, children went ahead at their own speed, and the results were very encouraging.

Experiments in Green County Iowe Schools

On the basis of a brief study of fifteen reading disability cases in Green County, Iowa, in January, 1925, a similar analysis of a larger series of cases was attempted in January, 1926 "to determine whether the association of these reversals ( $b$ and $d$, was and saw, etc.) with inability to learn to read was really significant." "The methods for diagnosis and treatment of cases were based on the comparison of the reading performance of 120 normal and 175 retarded readers. Some of the experiments showed remarkable gains.

In the Green County Laboratory Observation School eight children were admitted and treated for eight weeks during the summer of 1926. A year's gain in reading resulted. Another training experiment, called "The Cherokee 40

Arthur I. Gates and Mirium C. Pritchard, Teaching Reading to Slow-Learning Pupils, 1942, p.2. 41

Samuel T. Orton, Methods of Diagnosis and Treatment of Cases of Reading Disability, Genetic Psychology lonographs 4:No.4 and 5 ,October, November, 1928, pp.338. 
Experiment," was carried out in the spring of 1927. Volunteer teachers gave individual help outside of school hours. Gains from three-fourths to nine-tenths of a year resulted from the special help.

A third experiment called "The Council Bluffs Experiment", was conducted for six weeks during the summer of 1927. Seven children were given remedial reading instruction by group tracing and sounding, oral reading, and individual work as needed. Examination at the end of the six weeks' training showed an average gain of one year in reading ability.

In other cities similar experients were undertaken. Under individual instruction rapid progress was made. 42

Heck describes Oakland's basis of classification which was started in 1918. Besides normal sections, special classes know as accelerated, opportunity, limited, and atypical were formed in which the needs of all classes of pupils could be met more fully. Under these classifications the pupils who were retarded for various reasons, could return to their regular classes as soon as they had made up their work.

$$
43
$$

Backus, gives a brief history of the Washington

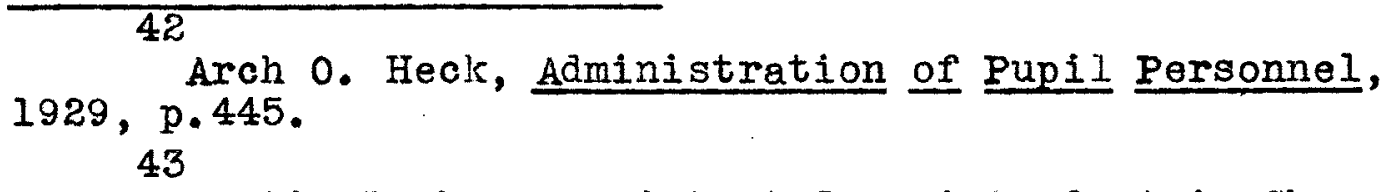

Bertie Backus, Assistant Superintendent in Charge of Character Education, Public Schools, Washington, D. C. 
Experiment in Character Education which "was inaugurated July 1, 1934, by the Board of Education of the District of Columbia public schools. Each school in the experiment tried to meet its own reading problem in its own way." The Monograph, "Remedial Reading" describes the experiment in the elementary grades, junior high schools, senior high schools, and vocational schools in Washington, D.C. Ten schools were selected and conditions within the schools were kept as normal as possible, teachers and counselors being selected from the schools in which they were to work. One phase of the character-education program was the study of the problems of those children who had difficulty in learning to read. Scientific procedures and measurements were used, the gains of the individual child were recorded on charts and tables, and a comprehensive program of remedial reading was described in most minute detail.

"The chief value of the study is a practical one: educators desiring to establish remedial reading programs will find here an account of such an attempt, with details of the methods used and the results obtained."

In the same monograph, a study which was made by Miss Mildred E. Sperry, at the Child Guidance Center, Pittsburgh,

Marion Monroe and Bertie Backus, Remedial Reading, 1937. 45

Ib1d., p. 158. 
Pennsylvania, is described briefly. It "indicates that favorable changes in behavior often accompany the correction of reading disabilities." Miss Sperry made a follow-up study of sixty behavior problems who were also reading-disability cases, with I.Q.'s above 80 . The study indicated the tendency for those children who make the greatest progress in overcoming reading disabilities to improve their behavior as well.

\section{Reports on Experiments}

Contributions to the conference on reading held in 1941 in Chicago, were part of a vigorous campaign to improve reading and to consider the "specific classroom problems that should be faced in promoting growth in and through reading at various levels of advancement."

In the reports on "Adjusting Instruction to Individual 48

Differences" were a number of interesting experiments calling attention to plans and procedures which seemed to aid in adjusting instruction to the needs of individual children. Some of the types of administrative adjustments are:

1. "Providing special reading instruction for pupils

Ibid. , p. 153.

47

William s. Gray, op.cit.,p.l. 48

Donald D. Durrell, 1941,p.79. 
with low vision, poor hearing, severe speech defects, or other conditions which particularly affect reading.

2. Classes for severely retarded readers.

3. Ability grouping in reading throughout the entire school." 49

In the same report by William s. Gray is an article on the "Reorganization of the Primary Grades in Minneapolis in a Single Administrative Unit." "The first four grades including kindergarten, were designated "The Early Elementary School" and the children spent a whole year in each grade with no acceleration during the year to a higher grade and no non-promotions. Instead each child was given a program according to his needs and allowed to progress at his own rate. The teachers were encouraged to remain with a class for two or three years.

No scientific research has been conducted to show what the effect of the reorganization has been on the children's development; but the supervisory and administrative groups in the school system agree that it has solved many of their problems and that success is found in the schoolrooms where the teachers and children "exhibit not signs of strain or insecurity, but rather deep enjoyment, satisfaction, and

$$
\text { Ibid., p.84. }
$$

50

Ibid., (Bernice Newell,) 1941, p.90. 
growth - both child and teacher growth."

51

Most children will be found ready for reading; others will not be ready, and for them an eitended reading readiness program must be planned.

Some psychologists and educators advocate the postponement of the teaching of reading until children reach the second and third grades. Below is a plan devised by the Winnetka Public Schools which proved that postponement was profitable.

Individual Plan of Instruction in Winnetka, Illinois.

\section{3}

Having found through experiment that it is safer not to teach children to read until they are mentally six and a half years of age; a controlled experiment lasting eight years was tried to see if there was harm in further postponement. There were two groups; the control group of pupils began to read with systematic instruction in arithmetic and spelling during their first yeat at school; the experimental group had a rich program of activities with no drills, nor reading classes during the whole day. For the first two years the control group was more advanced;

\footnotetext{
Ibid., p.90. 52

J. Wayne Wrightstone, Determining Readiness for Reading, No.6, p. 45 .

53

William S. Gray, op.cit., 1941, p.90.
} 
by the end of the third year, the two groups were approximately equal; by the end of the fourth year, the experimental group was ahead of the control group and continued its superiority through the grades. "This program of freedom from pressure.. has resulted in our having very few cases of remedial reading and in an exceptionally high average in reading ability." 54

Bernice Newell reports another study called, "Administrative Provisions for Individual Differences in Minneapolis." 55

"In this preliminary study of each child's basic skills special attention is given to reading needs of the more serious cases." In Grade Three a remedial program is given to retarded readers and continued through the intermediate grades and junior high school.

"The chilorem selected for remedial reading are grouped, in so far as is possible, according to the disabilities revealed in the word-recognition test and the oral-reading test, those children having similar disabilities and approximate achievement being grouped together. . The groups are kept rather small, approximately eight or ten pupils -

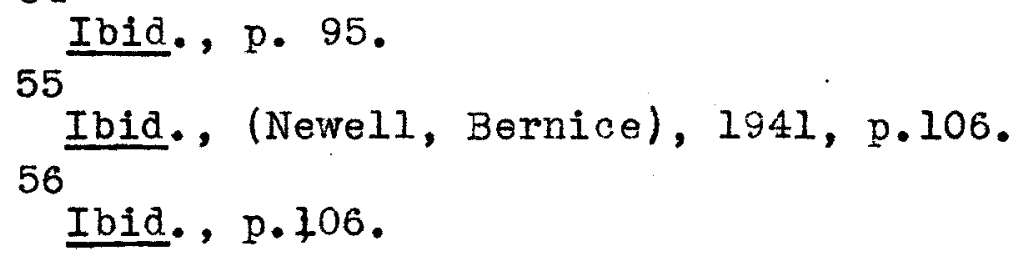


large enough to permit sub-grouping and small enough to allow needed individual attention."

This program is very similar to the one which has developed in the Mary D. Hill School Opportunity Class. The organization in Minneapolis, however, comprises the whole system of the elementary schools.

The Montefiore School in Chicago provides a combination of special school and clinical facilities. A study of 250 elementary school boys revealed retardation in reading of two to five years. "No doubt, reading disability was a factor in preventing proper social adjustment," since all boys are transferred to this school because they are socially maladjusted in the regular schools. The reading program is planned to overcome reading disability as a cause for social maladjustment and emotional instability. When many of the boys find that they can read, they cease to be problems and they begin to adjust in spite of other handicaps.

"In traditional schools, little has been done to help deficient readers, except to extend the hours of practice before or after regular school hours, or to apply some form of punishment." 59

57

Ibia., p.106. 58

Ibid., (Edward H. Stullken), 1941,p.309. 59

Gertrude Hildreth, op.cit.,p.669. 
60

Gertrude Hildreth tells of the Los Angeles plan which was adopted to handle special classes of children who were enrolled in regular classrooms where they would fit socially. Although they were retarded in reading they were able to do other school work fairly well. In almost every case distinct improvement and change in attitude were noted.

She mentions also a program conducted by a neighboring college in a Pennsylvania elementary school in which throe fields were included: narrative reading, reading of the history text book, and the reading of written arithmetic problems. In each subject, drills and special attention were given by the respective teachers. At the end of the drill period, the Lowry Intermediate Reading Tests were given, and as a result of the experiment, marked gains were noted on all tests.

In st. Louis, at the Washington University, there is an educational clinic "for pupils having difficulties in maintaining successful standards in the elementary or secondary schools." ${ }^{62}$ A remedial program for each child is set up on the basis of findings by the Department of Education and Psychology. Work with groups and individuals who have

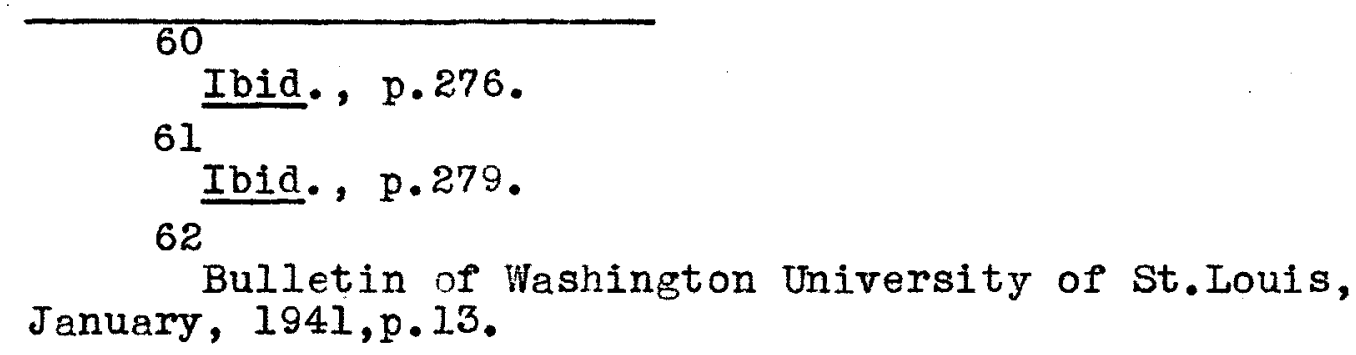


severe difficulties is provided for students enrolled in certain of the Education courses, who are preparing themselves to do diagnostic and remedial work in the public schools. Causes of difficulties and kinds of successful remedial work are summarized in class sessions.

Under the supervision of Mrs. Helen B. Keller, "Ad justment $c$ " rooms were organized in the Los Angeles public schools in September, 1926, to provide remedial instruction in reading.

The children in these "Adjustment C" rooms were nonreaders, some with marked disability. They were enrolled in regular classes where they fitted socially and where they often excelled in other school work. "Except in rare cases, non-readers are quite capable of taking part in all classroom work not directly dependent upon reading." 64 Fifty percent of the children eome from the $3 B, 3 A, 4 B$, and $4 \mathrm{~A}$ classes. For the first two years it is difficult to determine whether a slow-learning child is a non-reader except in very marked cases. This probably accounts for the fact that the greater percentage came from the third and fourth grades.

During five years, from 1926 to 1931, the adjustment

63

Grace M. Fernald, Remedial Techniques in Basic School Subjects, 1943,pp.151-156.

64 Ibid., p.152. 
rooms were maintained in various sections of the city as centers to which schools could sent their reading disability cases. Most of the children had intelligence quotients of 90 or better, but exceptions were often made and some cases with I.Q.'s below 90 were enrolled. The tables and figures show encouraging results and interesting data.

The Clinic School was established in 1921 at the 65 University of California at Los Angeles. Only cases of normal or superior intelligence are handled here; but often the children have extreme disabilities, such as, word-blindness and speech defects. Some have been stutterers, spatics, and epileptics. The children are grouped according to their difficulties. As soon as they have completed their remedial work, they return to the schools they came from and new children are put in their places. In the literature it will noted that the success of the slow learner is being considered as well as that of the more intelligent children, although actual work seems somewhat scattered and experimental. Some research has been done on the value of phonics, grouping of children according to achievement, the individual differences among these children and the various methods and techniques which may be used.

65

Ibid., pp. 3,4. 
Most of the authorities agree that children should not be forced to try to learn to read until they are ready. Thus they will not be faced with failure at the very beginning of their school life. The Winnetka, Illnois, schools have removed all fixed standards and have given the teachers utmost freedom to use their own judgment as to when children are ready to read.

At the Speyer School, in New York City, it is believed that for slow-learning children reading should be treated merely as one of the tools that may be employed in achieving a satisfactory educational adjustment.

Here also the children are allowed to progress at their own rate of speed, trying out new methods and materials especially suitable for slow-learners. In the Oakland schools this plan is extended to all children from those of limited ability to the accelerated classes. Los Angeles has launched successful experiments in many schools to provide remedial instruction in reading while children are adjusted socially in regular classrooms.

Conclusion.

Sincere efforts are being made to educate the slowlearners, experiments and adjustments have been made but there is still a long way to 80. The problem is a serious 66 Gates and Prichard, op.cit.,p.62. 
one and takes on vast proportions in the light of statements made by W. B. Featherstone who says, "In every sample of one hundred pupils selected at random from the elementary schools of the nation, there are at least twenty who must be regarded as slow-learners" which "means at least four million for the country as a whole... Ponder the consequences for the general welfare of permitting that number of future adults to grow up illiterate, uncultured, and uninitiated in the American way of life."

Special consideration to the progress of slow learners should be given, regardless of the methods used. The problem is in every school and the solution depends on the individual school situation. 
CHAPTER III

THE TEACHING OF REMEDIAL READING IN THE MARY D. HILL OPPORTUNITY CLASS 
THE TEACHING OF REMEDIAL READING IN THE MARY D. HILL OPPORTUNITY CLASS

In the following chapter an attempt will be made to present the importance of teaching reading to slow-learning children and then, specifically to give simple methods which may be used with groups of from two to ten pupils, or with individuals who need private coaching.

Attention will be devoted to the child with a reading difficulty, the objectives of the teacher, a description and classification of errors and remedial methods, oral and silent reading, games, lesson plans, drills, and some speech correction.

Importance of Reading.

In the curriculum of the elementary school no subject occupies such an significant place as reading. It is considered the most important learning tool for a child to master, not only for the gifted child, but for the less fortunate pupil in the slower group or in the ungraded class. It is also a social tool. If a child, growing up in this country, free to choose the things he wants to do is to be an intelligent and well-informed citizen, he must be a reader. Advertisements, newspapers, information about 
airplanes and machines, community projects, books for entertainment, comic magazines, and many other materials come into his daily experience. These all help to form his opinions and ideals, and to give hin information and recreation. "It is doubtful that any other more satisfactory and convenient means of communicating, preserving, and spreading thought, than reading, will ever be developed sufficiently to make it unnecessary for children to learn to read." 68

Dr. Zenos E. Scott says, "In teaching children how to read intelligently and with understanding, the foundation is laid for observation of fact - - the development of incident and motive; for clear thinking; for insight into the relation of ideas; for power to separate the significant from the insignificant; for power to organize and present ideas and concepts. From this point of view, reading is truly a basic art; the teaching of reading is the most fundamental of all subjects."

Unfortunately all children are not equally capable of learning to read. Many groupings of different levels are taught by all teachers in all grades. "Reading disabilities are frequently related to emotional strains and

Marion Monroe and Bertie Backus, Remedial Reading,p.2. 69

Zenos E. Scott, Course of Study in Reading for Elementary Schools, Louisville, Kentucky. (Forwod 1942.) 
undesirable attitudes and behavior," ${ }^{70}$ caused by failure in reading, or resulting in reading failure, or going hand in hand with the reading disability and related to some other factor, The large number of children needing remedial reading instruction justifies its being made a part of the curriculum in the public schools. Often there are children who cannot be reached even by the instruction given by a good remedial teacher, those children who become reading problems who have been in school for years, have never learned to read, and rapidy become retarded personality problems.

The attention of educators has been called to the seriousness of reading failure because recent experiments have showed relation between reading disability, school failure and behavior problems.

$$
\begin{aligned}
& \text { Conduct or behavior and the factors which } \\
& \text { influence conduct or behavior are all of } \\
& \text { one piece, -All of education has conceiva- } \\
& \text { bly an influence on conduct and all ele- } \\
& \text { ments or procedures in education which } \\
& \text { may influence conduct, must be taken into } \\
& \text { account in a scheme of character education. } 71
\end{aligned}
$$

Estimates have been made that from eight to twenty percent of school children have reading disabilities and

\footnotetext{
70

Marion Monroe and Bertie Backus, op.cit.,p.4. 71

Marion Monroe and Bertie Backus, Remedial Reading, p.4., quoting Frank Freeman, Journal of Educational Sociology, December, 1936,
} 
that from twelve to fifteen percent of the school population are sufficiently retarded to need remedial work. These large numbers present a serious problem which cannot be ignored.

Reading causes most failures in the primary grades. In the upper grades inability to read causes failures in geography, history, and even in arithmetic where problems must be read. The writer prefers primary cases where the difficulties have been diagnosed early. Older children present more difficulties because their reading disabilities are often related to emotional strains and undesirable attitudes and behavior.

Methods Adapted to the Child's Difficulties.

Each child presents a problem different from that of every other child. Teaching procedures must be changed and adapted to meet the individual's needs. Learning to read is a mechanical process which can be made a living thing through understanding. ${ }^{73}$ A child must be respected; his worthwhileness must be made positive to him; then he can be reached. It is necessary, therefore, to select methods to meet particular problems.

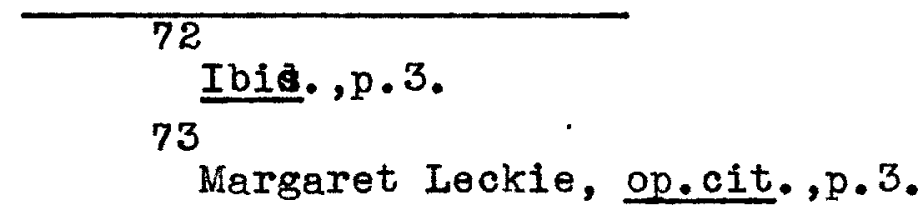


Attitude of Teacher and child.

The teacher should create a situation as natural and enjoyable as possible. The first lesson will be the most difficult to pupil and teacher alike. It is during this period that the "You and I Fellowship" must be established. The teacher needs to consider her procedures in terms of her own personality and her relationship to the child. Teachers often forget that they are important experiences happening to children, especially the coach teacher who may succeed in bringing her pupil encouragement and success that will color the rest of his school life. She should avoid creating an impression that he is taking special work as a punishment for poor reading. She should be generous in her praise, point out improvement and simplify drills to the extent that there will be more successes than failures. With methods adapted to his difficulties, an encouraging teacher can soon point out to the child that he is making progress.

\section{An Oral Reading Test.}

A diagnostic test will indicate the individual's outstanding errors. The Gates Oral Reading Paragraphs is a simple test, agreeable to children who a re encouraged by the sthort, easy paragraphs at the start. As the child reads

\section{Ibid., p. 3.}


aloud from one copy of the test, the teacher marks the errors with a pencil on a similar sheet. Words mispronounced or unknow are encircled; words omitted are encircled with a twisted curl on the top $\boldsymbol{\xi}$; words or phrases repeated are underlined. No mistakes on one paragraph or only one, gives a score of four; two mistakes give a score of three; three mistakes give a score of two; four mistakes give a score of 1; more than four mistakes give a score of zero. The scores are added to make a raw score. The "B-Scores", which accompany each packet of tests, in terms of the raw scores will give the pupil's rating or grade placement.

\section{Raw Score}

1

2

3

4

5

6 etc.

$$
\underline{B-\text { Score }}
$$

$$
1.4
$$$$
1.6
$$$$
1.8
$$$$
1.9
$$$$
2.1
$$$$
2.3
$$

Raw Score

21

22

23

24

25

26 to 34

\section{$B-$ Score}

4.7

4.9

5.1

5.2

5.4

8.0

If a child's raw scores total 5 , this indicates a B-Score of 2.1, that is, he is doing work equal to the end of the first month in the second grade. A raw score of 25 indicates a B-Score of 5.4, or work equal to the end of the fourth month of the fifth grade.

This test should be given again every four or five nonths to check for progress. In this way, the pupil will

William S. Gray, Standardized Oral Reading Paragraphs. 
be encouraged and the teacher will discover which objectives have been reached and which points need to be clarified.

An Experience With a Very Slow Group in the Mary D. Hill Opportunity class.

The following routine was used in teaching a group of four very slow children, aged eight, nine and ten who knew no words after all of the accepted primary methods were used with them. The teacher discovered that they had an ear for phonetic combinations; yet they did not know which letters were combined to make them. For instance, if the teacher said, "What does $i-s$ spell?" or "What is a-m?" or "a-t?" they would always give the correct sound. But if she said, "How do you spell 'is', or 'at' or 'am'?", they did not know which letters to use. They did not know is or at or am when these words were pointed to on the board. The teacher asked them if they "knew their A B C's," Arthur, who was nine, could say them all in order; Albert, who was ten, daid the first ten or twelve letters and then skipped over to $X Y Z$; Billy, who was eight, could not say any; and Juanita, who was ten, said, " $a, b, c, "$ and gave up. The teacher told them ${ }_{n}$ saying the alphabet was not important if they could read the letters from the board or from a card. She printed them in order on the board and only the first two boys could read them. In fact, they were saying the letters, not reading them. The teacher 
asked them to read only the ones to which she pointed. The few they knew were $a, b, c$, and $x, y, z$, because of their position at the beginning and the end of the line of letters. Even these were not known when the alphabet was erased and the letters isolated.

The teacher proceeded to call attention to the formation of certain letters, $1 . e .$, the round $o$, the $b$ with its straight back, the $t$ with its cross piece, etc. only a little porgress was made during this lesson.

The next day the teacher gave each child an envelope containing three-inch cards with the 26 letters of the alphabet printed on the front and back. A small red dot was placed above each letter to indicate the top of the card. Each letter was on a line. After working with a few of the cards, four very different letters $a, m, t, x$, were assigned to be learned for the next day. When the class met again, the teacher found that only the a had been really learned. She assumed she had made unwise selections; so she chose three other letters, e, s, v, plus the original a. She told the children that the $e$ was like the o with a piece bent back, the $s$ was a snake and sounded like one and the $v$ was for Victory. Billy learned $v$ immediately and always called the letter, "V for Victory".

\section{A Kinesthetic Aid}

After three or four days with no progress being made, the teacher decided that these children needed a kinesthetic 
aid. Besides making up a story about each letter, such as "f is a candy cane", "m has two hills", "o is a round doughnut", "k is made with three sticks", stc., she had the chilaren trace each letter with the index fingers as they said, "s is a snake", "t is an umbrella", "x is a cross mark", "z is a 8ig-zag". As Billy made the three parts of the $\mathrm{z}$, he said, "Zig, Zag, Z!"

From that time on they had no trouble learning all of the letters. They not only looked at them; they had an interesting association for each one; and they had a feeling for the shape of each letter.

One seldom finds a group as slow as the above-mentioned one, especially since all four children had reached a reading readiness level and should have begun to read simple words and sentences.

Grade-Placement of Opportunity Children.

In September, 1945, eighteen children were enrolled in the Opportunity Class, eleven from the Mary D. HiII district, and seven special cases from other city schools. Those entering the school for the first time were tested for placement in the regular grades in the school.

For each child with different levels of achievement, a program was worked out with the regular grade teachers who were to give them extra time and special attention. In testing the opportunity children, a distribution 
of reading scores from 0.0 to 4.2 resulted in the formation of five groups. To these groups were added twenty-three regular grade children whose reading scores placed them in one of the five groups. (They were pupils in all grades, from $2 B$ through 6A.) The majority of them had been carried over from the term before and only a slight re-arrangement was necessary to accommodate the new pupils. There was no individual coaching during the fall term.

In January, however, when there was no possibility of starting another beginning group, a new child from a fourth grade in a private school, a non-reader, entered Mary D. Hill School. While awaiting the disposition of this case by the Board of Research, the Opporunity teacher has placed him in a third grade where he seems to fit socially, and has set aside a short reading period for his individual instruction. His work is included in the "Typical. Day in an Oppotunity Class" page 69.

\section{Oral Reading as a Part of Remedial Instruction.}

After many years of silent reading in which oral reading

has been frowned upon, teachers are realizing that they have been neglecting a valuable tool by which they can keep constant check on their pupils' reading progress. Many bad habits, such as careless skimming, guessing, mispronounciation and wrong interpretation, have developed without the teacher's knowledge. Silent reading should be checked 
carefully through questions by the teacher, the answers to which should be read aloud. Other devices, such as dramatization and periods for original questions, sharing information or verifying statements by the pupils, require oral reading.

Judd and Buswell stress the point that oral reading should receive the greater emphasis until the rate of readIng approaches the rate of speech, which is about the fourth grade. When a pupil reads orally, he has the best opportunity to sense his own mistakes. He adds new understanding to the sentence or the passage he has studied." "There is no doubt that many pupils in the primary grades are retarded on their reading growth because of lack of adequate opportunity to read orally." 79

. In remedial work the teacher must know exactly which urrors the pupll is making. All reading, therefore, must be oral for the first few weeks. Later, short periods of silent reading may be used during the coaching hour. Very easy material must be read, however, in order that few

Vol.II, No. 4 .

Charles J. Judd, Reading, Itg Nature and Development,

77

Guy T. Buswell, An Experimental Study in the EyeVoise Span in Reading, Educational Monograph, No.17. 78

Course of Study, Reading for the Elementary Schools, Louisville Public Schools, Louisville, Kentucky.

79

Roma Gans, op.cit.,p.23. 
mistakes will be made. After checking quickly for content, the teacher may ask the children to read the lesson orally for a double-check.

At all times in the remedial work, questions and corrective devices should be used to check the child's comprehension of material read. This, after all, is the final goal of reading. The majority of children are able to get the meaning of passages read. Those with limited ability are trained with simple questions requiring simple answers.

Text: Bllly lived in the big red house.

Questions: 1. Who lived in the big red house?

2. What are the two words that tell what kind of a house Billy lived in?

With beginners, it is important that they read orally in order that they realize that they really are reading. With experience and a gradual training to find simple information silently, they begin to increase their speed and accuracy of word recognition. Soon, whole pages and sections can be read silently with only an occasional oral passage read as a check-up.

Selection of Reading Material

The selection of reading material is important. It should be full of action and easy to read. It subject matter should suit the child's age level, and at the same time, should be written to suit his reading level. This 
kind of material is scarce and hard to find. "Studies have shown that physical make-up of material has some effect on reading choices." ${ }^{80}$ Children like large books rather than small ones. Brightly colored book covers are of greater interest to them than brown or gray ones. Books with large, clear print and bright, colorful pictures and illustrations also appeal to young children.

When beginners leave the pre-primer stage and are given hard back books, they really feel that they are making progress. Nost new books do not have grade levels printed on the outside; and children who are sensitive about their backwardness, like paper covers for their books so that no one will guess their grade levels.

\section{Series Books}

Series books are very valuable. Their vocabulary is over-lapping, the repetition of drill words comes without effort, and no words are lost as in the case when a new series is introduced. Children like series books because of their acquaintance with the characters, their pictures, and their further adventures.

The number of pre-primers that accompany any one reading series varies from one to three. "It would seem,

Mary E. McCarthy, op.cit.,p.4. 
at least, that it is sound psychology to read a number of pre-primers before attempting to read small type, more mature content, and more complex sentences of the average primer." 81

One of the best is the Gates-Huber-Peardon series 82 beginning with the pre-primer, off We Go, and ending with the fourth reader, Let's Look Around. In off We Go there are 42 new words which are found again plus 21 new words in the second book, Now We Go Again; all of these 63 words appear in the third book, Jim and Judy, plus 146 new ones. They are grouped in the back of the books listed under the numbers of the pages on which they first appear. The first reader is, Down our Street, the second is, We Grow Up, the third, Wide Wings, and the fourth, Let's Look Around. The authors of the fourth reader are Arthur I. Gates and Jean Ayer. Another excellent series is the Easy Growth in Reading Series, Pre-Primer through Grade Six, by Gertrude Hildreth, Annie Lou Felton, Mabel J. Henderson, and Alice Meighen.

Regardless of the material used, the child must succeed. He must be satisfied that he is learning.

81

E. Swan, The Relative Difficulty of Abstract Words and Words With Meaningful Concepts, Master' $\frac{\text { Costs, }}{\text { Thi- }}$ versity of Idaho, 1939.

82

Arthur I. Gates, Miriam B. Huber and Celeste C. Peardon, Off We Go, 1939. 
The Mary D. Hill School has been fortunate in its opportunities to obtain suitable books. The primary supervisor, Miss Mary Browning, at the Board of Education, and the supervisor in charge of Special Classes, Miss Mary May Wyman, provided a number of good series readers and book-lists from which to order supplementary material. Money, made from the sale of old newspapers and magazines brought to school by the children themselves, was made available to the teacher who was able to select books which were within the scope of the children's understanding. Thus, a variety and an unusual selection of good readers, colorful and bright, were purchased for the children of the Opportunity class.

\section{Care of Books}

As soon as the children begin to use books, training in the care and handling of books should begin. A list of rules should be made and observed.

How to care for books:

1. Have clean hands.

2. Use a book-mark.

3. Open the book carefully.

4. Turn the pages carefuliy. 83

A Typical Day in an Opportunity class.

The children enrolled in the opportunity class report

83

Course of Study on Reading, Louisville Public Schools, op.cit., p. 19 . 
to the "Coach Room" and their attendance is recorded by a representative of the class. They proceed to the home rooms to which they have been assigned through grade-placement tests. They remain in these rooms until their individual programs call for a change of teacher or class.

Meanwhile, the coach teacher has early morning duties to perform before her groups are called for remedial reading instruction. She conducts a simple library service for slow children in her room where they feel free and unashamed to borrow the easy books for the extensive reading activities in which the grade teachers are interested this semester. The children exchange the books as they finish them, and the teacher records the transactions and helps with the selection. The use of books designed for average children presents a difficult problem to the teacher of retarded children who often resent being given "baby books". An assorted set of bright, colored, beautifully illustrated story-books differing greatly from the ordinary school readers has been sent to the Opportunity class by the Supervisor of Special Classes.

After the library business has been completed, the teacher may have a new child to test for grade-placement or for a reading score. The reading test procedure is as follows:

The Gray's Oral Reading Paragraphs test is given according to the directions accompanying the sheets. 84

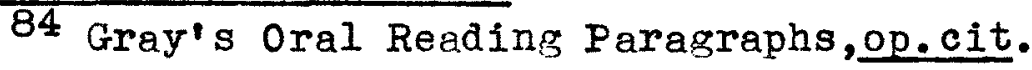


Errors such as addition of words, omissions, mispronounciations, etc., are recorded on a test by the teacher while the child reads aloud from another copy of the test. He begins to read Paragraph I regardless of his grade and continues until he has made seren errors in each of two consecutive paragraphs. The teacher computes his score and if he is a candidate for remedial reading instruction, he is assigned to a group and placed with a regular grade teacher for a trial period.

Reading With the First Group.

After these preliminary duties have been disposed of, the coach teacher sends for her first group who read on a second grade level. She has worked with most of these children over a period of many months, and so, is able to give definite instruction in several reading techniques, such as phonetic drill, finding central theme of a paragraph, reading for content, etc.

On this particular day the group is reading, "Dudley Duck in the Well, " by Elsie Reid Boyleston, in a second reader, The Easy Road. In a previous lesson the first half of the story had been prepared and assigned for home study. This is to be read aloud as a check before proceeding with

${ }^{85}$ Gertrude Hildreth and others, The Story Road, Easy Growth in Reading Series, 1941,pp.2-12. 
the story. There were a few troublesome words and phrases yesterday which should be reviewed today.

The teacher says, "Lucy, what is the duck's name?"

Lucy: "Doodley Duck."

Teacher: "Spell the first name while I print it on the board." (Lucy spells 'Dudley'.)

Teacher: "I w11l write his last name, too. Do you notice that both of his names start with the same two letters? Do you know his last name? Say it." (Lucy says 'Duck'.)

Teacher: "Now say it again, but leave off the k-sound." (Lucy who has had considerable phonetic drill gives the correct sound.)

Teacher: "The same Du-sound is in the first name. Say it." (Iucy says it correctly.)

After similar drills on two or three words with other children, the first half of the story is read orally, each child reading a page.

Teacher:" Everyone gets a "one" today except Aline; but she's new in our group and it will take a few days for her to catch up." (To Aline) "You still are having trouble with the word alone, aren't you? Maybe this card will help."

(Teacher writes the word on a card and asks the child tofrace over the word with her finger spelling it as she traces. She is given the card to take home and trace and 1earn.) 
Teacher: "Now children, let's look at the next page. Whom does Dudley next meet?"

(Children answer from the picture - "a snail".)

Teacher: "Find his name on the page and tell me what kind of a word it is."

Mary: "It's a "joker" word with a double vowel sound." Teacher:"Will you tell Aline what you mean by a double vowel?"

(Mary points to a card on the wall upon which is printed the verse: "When two vowels go walking, The first one does the talking.")

Teacher: "Which vowel in snail does the talking?" (Answer - a.) "What does na spell?" (Children answer correctly.) "Then what is the word? Do you know any more words which sound like snail?" (Children give mail, sail, rail, hail, etc., which the teacher prints on the board.)

Teacher: "What does Dudley want to know about the snail?" (Answer - how he got in the well.)

Teacher asks other content questions covering a paragraph or two at a time, such as:

Is Dudley worried about staying down in the well? (There's a difference of opinion on this.)

When did Dudley decide he had better try to get out? How did Dudley try to interest the frog in the outside world?

How did Dudley trick the frog into telling his secret? 
What is Dudley saying Hurrah for now?

These questions are sometimes answered in the children's own words, but more often are read aloud from the book.

After a few comments on the ending of the story, the fine secret the frog had, the last half of the story is read orally so that no points will be missed and no difficult words oterlooked. If strange words are found, a drill similar to the one first one may be used, or just the ordinary word drill on the board may suffice.

When the teacher locates a sound which is frequently confused, she should exercise much care in presenting the the letter, its form, its sound, and its relation to other letters in the word.

After the children see that their marks are recorded in the little black book that lies within reach on the reading table at all times, they depart for their respective rooms. Some are to contact the members of Group II whose reading period follows immediately.

\section{A Reading Lesson with Group Two.}

Group, has also been with the coach teacher for months but has made less progress than Group one. This is undoubtedly due to the lower mentality of its members. They have, however, made greater gains in the past five months because they have at last reached the level of readiness through painful repetition, word drill, phonics, simple questions 
and answers. They have reached the first reader, level two, in the Fasy Growth in Reading Series, and today's lesson is "Bushy Tail and Chatter-box." by Nicholas Radlov in the reader called Good Stories. Three children who knew their lesson perfectly the day before, will act as audience to the other six children who will read the story aloud with few comments, from the teacher. The audience does not hesitate to stop and correct a reader's mistake. The audience also passes judgment upon the marks for the little black book. Teacher: "Turn to the next picture. What do you think the frog is saying?" (Answer - Ker-ohug.) "It may be a little too early to read this story as far as seasons go. Why? Turn on the next page and see."

(Children see Spring has come and know that it is not spring in January.)

With this group the teacher reads much of the story aloud with the children to keep the thread of thought intact, and to provide very simple questions. These are children with short memory span, flighty attention, tone deafness, word blinaness, disabilities that often accompany low mentality. Only the simplest exercises are attempted because of feeble reasoning power and slow reactions.

Questions like:

See if you can find out what the frogs know.

86

Hildreth and Others, op.cit.,pp.36-34. 
Who are the new people in the story? (Find in picture.) Why did they come out of the water?

Did the frogs tell their secret?

A turtle came out of the water. Why?

How many people are out now?

What did Mrs. Duck answer?

Why did Mr. Robin come out?

Just then - what happened? Don't guess from the picture. Find the line in the story.

After the story has been read, a word and phrase drill made up of the children's own errors is printed on the blackboard. If time permits, the whole story should be read again with special attention for the words and phrases on the board. If not, then only the sections or sentences in which the drill words are found will be read.

The children in this group act as messengers for Group Three whose lesson will begin.

\section{A Reading Lesson with Group Three.}

Group Three is composed of seven ungraded children whose reading scores averaged 0.2 in September. Their average chronological age is 11 years and 7 months while their mental ages average 7 years and 11 months, making them 3 years and 8 months retarded mentally. They have been in school from three to six years and have not learned to read. These children, then, may be classified as nonreaders who 
have "failed to learn to read after systematic instruction. 87

in a normal situation," although they are low mentally. Today their lesson will be "Mr. Rooster and the Ducks" which was prepared yesterday and read at home, and "Little Elephant and the Water" which will be introduced today and prepared for tomorrow. They are found in Fun in story, primer level two, of the Easy Growth in Reading Series.

After the first story has been read, page by page, with every word checked and re-checked if found to be troublesome, the new story is talked about, the pictures are inspected and the characters are discovered to be old friends met before in the level one primer.

Iindsey: "I know who this is - Little Esselleft!" Teacher: "Children, let's teach Lindsey how to say Elephant."

The teacher remembers that Iindsey did not learn the word in the other book, but hoped he might acquire it this time. She knows that Lindsey is anxious to correct the baby-talk he has used for ten years which consists of "top" for "stop", "dem" for "them", "widale" for "little." He watches the teacher's lips and tries hard. Sometimes he succeeds with the word, sometimes he does not; usually he

87 p. 436 .

Arthur I. Gates, The Improvement of Reading, 1935, 88

Hildreth and others, op.cit.,pp.36-51. 
forgets unless the word appears often. The teacher knows that a formal phonetic drill or an explanation of the phsound would be wasted effort; so she divides the word into two sounds, not written, only spoken - ellie and fant.

Teacher: "Can you say fan?

Iind sey: "Fan."

Teacher: "Now put a $t$ on fan. What does fant spell?" (Child answers correctly.)

Teacher: "Now say ellie."(He does so.) "Now put ellie and fant together."

Lindsey: "Ellie-fant."

Teacher: "That's right. Now say it faster. Bring the two parts closer together." (Child says the word hesitatingly but correctly.)

The teacher then lets all the children say elephant. to check on other speech defects in the group and to save Lind sey some embarrassment.

Teacher: "Now let's see what has happened to Little Elephant."

The children can see from the picture that the elephant falls into the water.

Teacher: "Find the line that tells that he fell in." (There are only six lines on the page.)

Teacher: "How did he happen to fall in?"

Charles: (after reading, "He looked in the water. He 
looked and looked and looked.") "He looked too deep, and so he fell in."

Teacher: "Who would like to read the whole page?"

(One child reads it.)

Teacher: "Let's look at the next page and see who has come into the story."

Childeen: "A tiger."

Teacher: "Look over the page and see what kind of a tiger he is." (Children look at picture and say mean and yellow.)

Teacher: "You'd better read and not guess."

Billy: "He is Baby Tiger."

Charles: "He's a good tiger, because he says, "Can I help you?" "

The next two pages are read easily enough because there are no new words. On the last page of the assignment where Baby Tiger falls in, too, the teacher says:

"How does Baby Tiger try to help Little Elephant?"

Billy: "I could read the page if I knew this word." (He points to catch.)

The teacher prints the word on the board.

Teacher: "Do you see any little words in it?" (Children spell out at and cat.)

Teacher: "If you take out the word cat, what do you have

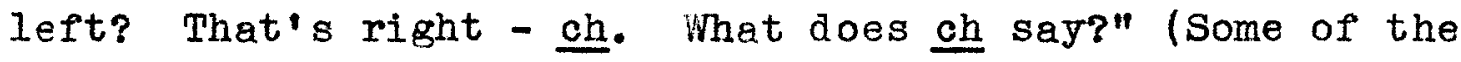


children know it.) "Now let's put ch on cat and what do we haver" "Catch", they all say in chorus.

Teacher: "Now Billy, do you want to try the page? We'll help you if you need it." (Billy reads.)

Teacher: "And so Baby Tiger fell into the water, too! Well, we'll have to wait until tomorrow to see what else happens. That's all we'll have time to work on today. Let's go back to the beginning and see if we can read it all." Practically all of the reading in this beginning group is oral because both teacher and the children must know which words they do not know and which errors they make. only short passages are read silently to give simple training to very feeble reasoning powers. Five of these children will be transfered to straight ungraded classes in other city schools as soon as places are available. They will be replaced, as members of Group Three, by other children selected from the slowest in Group Two and from other classes in the school.

After Group Three's lesson the teacher takes a combination recess and lunch period, following which she has an individual lesson with the new pupil whose placement depends upon his test results which have not $\operatorname{come}$ from the Bureau of Research at this writing. He is an absolute beginner in reading although his number work is on a third grade level. At the time of the testing at school it was found that he 
knew most of the alphabet and the two words to and in. He could spell and write boy and man. The third grade teacher found him eager to learn to read; but in a week's time during which she has worked with him in a very easy book, he has not retained a word.

This week he has been turned over to the coach teacher who believes that she can teach him by the hand-kinesthetic 89

method. He has been given a word file in which he can place word cards under the proper letters. On the word cards are written or printed the words in the first lesson in the book he wants to read.

In his first lesson, he is given his choice of many easy books. He chooses a paper-back pre-primer, off We Go, because he wanted the easiest one he could find. After looking at the pictures of the characters, he asked their names.

Teacher: "The boy is Jim. I will print it on a card for you."

Eugene: "Does this say Jim?

Teacher: "Yes, can you spell Jim?"

Eugene did not know the letters $J$ and $m$. The teacher spelled the name for him.

Grace M. Fernald, op.cit.,pp. 32-47. 90

Gates and Others,op.cit. 
Teacher: "Now you spell; it as you say each letter, let your finger slide over the word."

This was done two or three times. Then the word was found in the story. Looking at the picture, the teacher asked what Jim was doing. (Answer - He is riding a scooter.)

Teacher:"That's right, and the story says, Jim rides. I'Il make a card for rides and we' 11 have the whole sentence on cards. Now trace the second card and spell the word as you go. Now what is the boy's name?" (Answer - Tom.)

Teacher: "Let's trace the word again and see what it feels like." (Eugene traced and said, Jim.) "Now trace both words on the page and see if you can read what the boy does." (Answer - Jim rides.)

The same procedure was followed until Eugene had learned Jim, Judy, rides, said, too, I ride. These words on cards were placed in his word file and taken home with his book. (After this boy succeeds in building a fair reading vocabulary, an attempt will be made to work him inbo a small group where more formal reading will begin and continued individual help can be given. Eugene's present schedule may be found in chapter one under "Typical Individual Schedules," on page 27.

After the private lesson with Eugene, Group Four reading at a third grade level, and Group Five, beginning fourth grade eeading, are called in turn. The children in these 
groups have been reading in the opportunity room for many months and have had quite intensive drill in phonetios, both incidental and formal. They are capable of attacking new words alone, although the teacher often takes words out of the lesson for drill, as is mentioned in the typical lesson below. These children are still in need of oral reading, lest bad habits, such as mispronounciation, guessing, etc., should return. The following lesson plan is typical for Groups Four and Five, although lessons entirely silent or entirely oral are planned as need or occasion for them arise.

A Typical Lesson Plan.

Each lesson is divided into three parts:

(1) Introduction. Interest is aroused in the content of the lesson by recalling related experiences or by making vivid, meaningful association with the new words in the lesson. Free discussion is discouraged. The new phrases which are expected to be difficult are printed on the board as answers to factual and reasoning questions asked by the teacher. They may be related or unrelated to the lesson. The new phrases are read and re-read before the lesson begins.

(2) Reading the Lesson. After the pupils have had pratice in reading the phrases from the balckboard, they are asked to find them in the book as answers to thought questions. Sentences containing the phrases are read orally. 
Questions such as the following are asked:

Why was Mr. Zabriski told to wait until the passengers were looking out of the train windows?

What did the lady say when she saw the seal in the bathtub?

Mary, read it the way you think the lady said it. Why do you think the word, whole, has quotation marks around it?

Later, questions may be printed on the board to be read silently. Answers may be read orally or told in the child's own words. Finally, the entire lesson is read orally, page by page, by several pupils.

(3) Drill and check-up. Drill on the new words and phrases follows the reading of the lesson. Particularly difficult letter combinations are pointed out, incidental phonics drills are given with lists of family words, similarities and differences in words are noted, familiar words in difficult new words are found. (i.e. in and side are in inside; neigh, or, and hood are in neighborhood.) Attention is directed to the short vowels, the initial consonants, and the endings of words. Often, reviews or reading matches (like old-fashioned spelling matches) are given, thus affording the children practice on reading page after page of familiar material.

Except for an individual lesson which should last only 20 or 25 minutes at the beginning, all groups have periods 
of from 40 to 50 minutes of remedial instruction.

\section{Phonetics.}

"The whole study of phonetics is in a state of con91

troversy." School people have not directed much attention toward it and any experimentation at all has been in isolated situations, with various and heterogeneous groups of pupils and over insufficient length of time. It takes its turm as a fad and is discarded, forgotten, and revived again. Since all types of reading methods should be encouraged, the study of phonetics should be given more attention and continued long enough to measure carry-over effects. 92

"The method of teaching phonetics, when first introduced into American reading instruction, was usually that of having the child sound each letter separately by initating an exaggerated enunciation by the teacher. . " 93 Later, stories. were told about the relation between the letter sounds and the calls of animals and birds, and the sounds made by objects, such as engines, the wind, etc. The method now most generally used is through ear, eye, and volce training with rhymes, fanily words, and sounds from known words. Incidental teaching of phonetics often comes in the regular lessons,

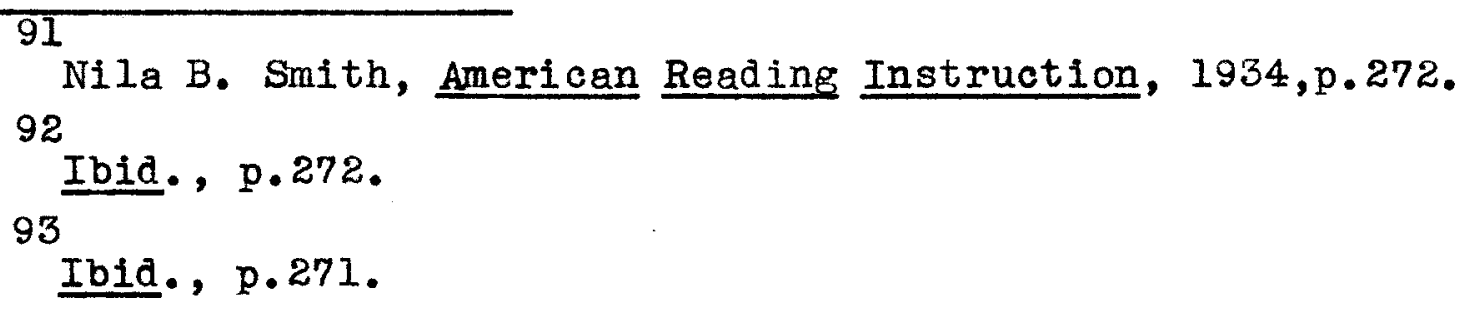
92 
with practice later for individuals or groups that show a definite need for help in attacking new words.

Certain cautions should always be remembered in teaching phonics to slow-learning or mentally retarded children. They should be taught systematically so that the children will be able to use them when needed. Phonics introduce mechanics of reading and are only a means to the end, which is comprehension in reading. Mere word-recognition does not necessarily produce effective reading. Since the English language is not entirely a phonetic language, many words must be taught by sight, as wholes, without attempting phonics. Words which are unphonetic and cannot be sound ed out are known as jokers, according to Roma Gans. When children begin to rely on phonetic analysis of new words that they meet, they should be warned that there are some words which will confuse them if they do not remember that they are jokers. They should be encouraged to look for new jokers. Much interest in words is evidenced in a hunt for new words if a list is kept. Such words as know, one, sure, and gnat, are ones to be remembered as tricky words, words to be recognized at sight. As a result of the neglect of phonetics in the reading program, many children in all grades cannot read easy material

94 Roma Gans, Guiding Children's Reading,p.40. 
and have no means of attacking long or new words. These children a re elassified as remedial cases. They lack selfconfidence, give up easily when they meet new words, and read as little as possible. All readers, rapid and slow, should be taught the association between sounds and letters or combinations of letters. Some pupils do not need much help; butothers demand teachers' attention for years. "The majority of vowel and consonant errors may be corrected by discrimination exercises devised for each confusion. . , and by adapting methods to fit each child's particular difficulty, whether auditory, visual, etc.,"

A variety of discrimination exercises may be devised on the basis of errors made by the children. Books on speech correction have interesting suggestions which may be adapted to phonetics games. They should be used whenever the confusion appears, in reading lessons or during phonetic drill periods.

The teacher must use her own jud ment as to which sounds are to be drilled on, which to be introduced to the children, and which to be taken incidentally. In adapting her work to her own particular situation, she must consider her individual children and their needs. She must find an exercise to help each child. One child hears the sound and knows it; another child must feel it in his mouth, or

95 Monroe and Backus, op.cit.,p.55. 
on his lips, or in his throat; one may watch the teacher's lips and imitate while looking in a mirror; another may have to trace the letter at the same time.

Two of the sounds most frequently confused are ch and sh. The following type-lesson may be used with groups from the $0.0^{96}$ level to those ranging from 3.0 or 4,0 . Usually, children of higher levels have corrected this error, but an occasional review is helpful.

Teacher: "The ch sound is spelled $c-h$ and says what the engine says, 'Ch-ch-ch", as it pulls a heavy train up a long hill. It is the 'train sound'. I will give you a number of words containing ch: each, vatch, witch, such, much, switch, etc. Does the ch sound come at the beginning or at the end of the words?"

Children: "At the end."

Teacher: "Now I will give some words which have the ch sound at the beginning: chin, chair, chill, chimney, choo-choo, etc. Who will give me some more ch words?" (Children give words.)

Teacher: "Now we shall play a game of listening. I shall give you a list of five words. All except one have a ch. Tell me the number of the stranger word in the ch family: 1. chop, 2. chore, 3. chew, 4. sew, 5. chain." (Children answer No. 4.)

96

B-Score, Gates Oral Reading Paragraphs. 
After four or five such oral lists, the teacher makes the game more difficult by introducing sh in the ch list.

Teacher: "Tell me the stranger in this list: 1.chum, 2. char, 3.ship, 4. chart, 5.chimney." (Children answer, No.3 - ship.)

Mention of the sh sound, however, should be incidental until the ch sound seems fixed.

The same type-lesson may be given for sh on another day. After both sounds have been learned, another game may be used as a further test. The teacher prints four or five

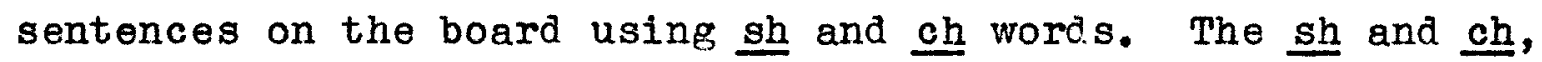
however, have been omitted and blanks indicate where they belong. The children put in the correct sounds.

Sample sentences:

1. The _air is beside the table.

2. The train says, "_-o! _-

3. Mother says, "___ __ ", when baby is asleep.

4. The white _ip was sailing on the water.

5. The wat_says, "It is one o'clock".

6 . Billy has a new pair of _oes.

Remedial procedures such as these give the child a tool with which he can work in figuring out a new word like church. If he remembers his sentence, "Ch is the train sound", often he will say, "Choo-choo", then "ch,ch!" He will probably know the the ur sound. Thus, he will have the train sound, ch-ur-ch. This is called sounding out a word. 
Source of Obtaining Drill Words

our drill words should be taken from the child's own errors or from new material which the teacher feels the child will miss. They should be arranged so that they may be broken up phonetically, either printed on the blackboard, on cards, or on mimeographed sheets. A short period before and after the reading lesson should be devoted to drills on these words. For variety, little games may be played with these drill cards.

The Remedial methods should be modified to meet the needs of each individual. A child who can read on a second or third grade level does not need all of the drills given to non-readers. A fairly thorough knowledge of phonics, however, supplies a tool which every child should have. In the witer's opinion, it makes him feel secure in attacking a totally strange word and there will be no "blocking", just staring at the word until someone helps him. With a background of phonics, non-phonetic words can often be obtained from the text. Slow children, however, do not always recognize the words if they are isolated. These words, then, are the ones to which-a period of special drill should be devoted after the lesson.

Brotional Problems.

Remedial instruction in reading improves not only the educational achievement, but also affects emotional and 
personality problems.

Behavior problems which have developed because of childrens' failure at school, often disappear simultaneously with improved scholestic achievement. A pronounced resentment toward school together with feelings of inferiority and discouragement, will often be replaced by an air of confidence and satisfaction resulting from a happier social and educational adjustment. "Resistent children have become co-operative; apprehensive children have become selfconfident; discouraged children have become hopeful; socially maladjusted chiloren have become accepted to the group; flightly children have become attentive. . The remedial instruction must be continued until the reading achievement is in harmony with the child's other capacities and achievements." 97

\section{A Summary}

Slow learners need more preliminary preparation for reading as well as for other learning. Those who have been forced to begin reading at the normal six or seven years of age usually have acquired no reading skill, and after repeated failures, often develop unpleasant attitudes toward reading activities. "They should be older chronologically when 
98

instruction is begun." The subsequent success is often due to increased mental iraturity rather than to method. If a child, however, is nomal his disabilities should be discovered before bad habits are formed, before he becomes a problem to his school, his parents, his companions, and to himself. After a careful diagnosis of his case has been made, a remedial instruction progrem should be planned with follow-up work over an indefinite period of time.

The following suggestions are derived by Gertrude 99

Hildreth from successful work with slow-learners.

1. Continue in the preparatory stage as long as the children require it.

2. After reading is begun, continue as long as necesazy on the simplest reading exercises.

3. Provide for maximum repetition at each stage of learning.

4. Change curriculum standards for these children.

5. Place the child in a small class so he can have more of the teacher's attention.

6. Stop the teaching of reading in some cases entirely for a time and then lead up to its renewal by novel routes.

7. Reading as a functional process can be suocessful with slower children as with brighter children, provided they have real purposes for reading when they read.

98 99

Gertrude Hildreth, op.cit.,p.68l.

Ibid., p. $682-683$. 
CHAPTER IV

A STATISTICAL ANALYSIS OF READING PROGRESS

OF THE OPPORTUNITY CLASS 
A STATISTICAL ANALYSIS OF RRADING PROGRESS

OF THE OPPORTUNITY CLASS

From records kept from October 1936, to January 1946, on the progress of 254 children who have had remedial reading instruction in the Opportunity Class, it was possible to ascertain the number of months each child was given special training and the amount of gain or loss (in months) which he made. The Gates Oral Reading Paragraphs Test was given in September, January, and May of each year and the scores were recorded on charts which were displayed in the reading room at all times.

The number of months spent in the remedial reading program ranges from one to 65 months. The number of months gained or lost ranges from four lost to 54 gained.

The following five bar graphs show the number of children spending five months, eight months, nine months (one school year), eighteen months (two years), and twentyseven months (three years), in the class and the number of months progress each child made. 


\section{FIGURE I}

READING PROGRESS IN MONTHS MADE BY 43 CHILDREN WHO SPENT FIVE MONTHS IN THE OPPORTUNITY CLASS

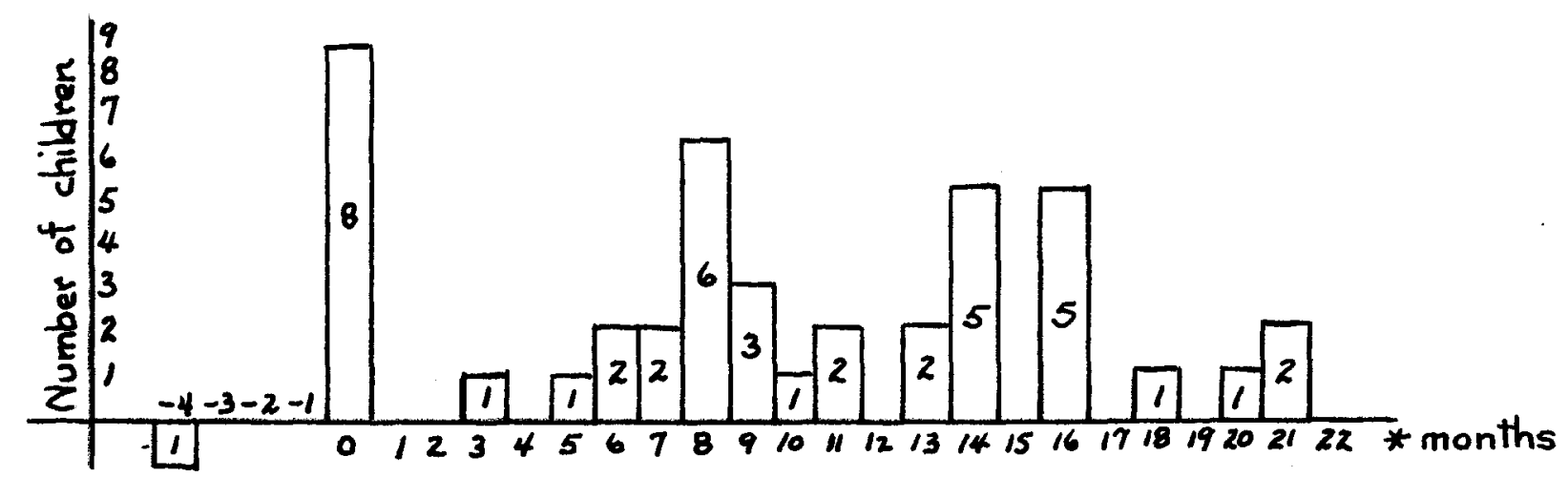

One child on the graph above lost four months because of illness. This is the only recorded loss in 254 cases. The eight children making no gain were low mentality cases. One child made retarded progress; one made normal progress (five months reading in five months); 33 made accelerated progress (more than one month's progress for each month's training.) 


\section{FIGURE II}

READING PROGRESS IN MONTHS MADE BY 19 CHILDREN

WHO SPENT EIGHT MONTHS IN THE OPPORTUNITY CLASS

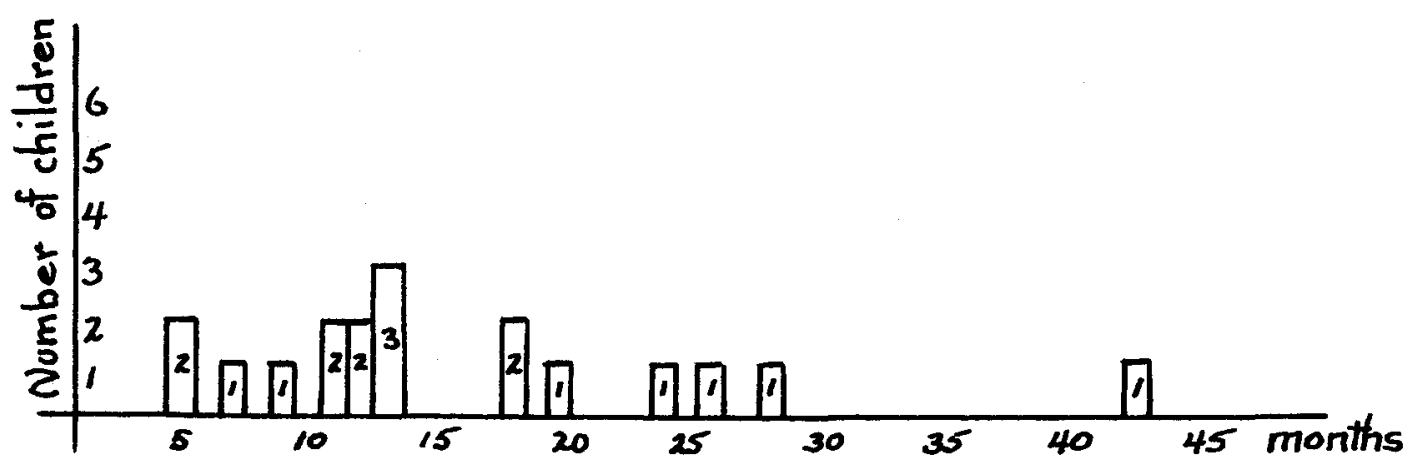

Three chilaren made retarded progress; 16 made normal or accelerated progress, and one child made 42 months.

\section{FIGURE III}

READING PROGRESS IN MONTHS MADE BY 55 CHILDREN WHO SPENT NINE MONTHS IN THE OPPORTUNITY CLASS

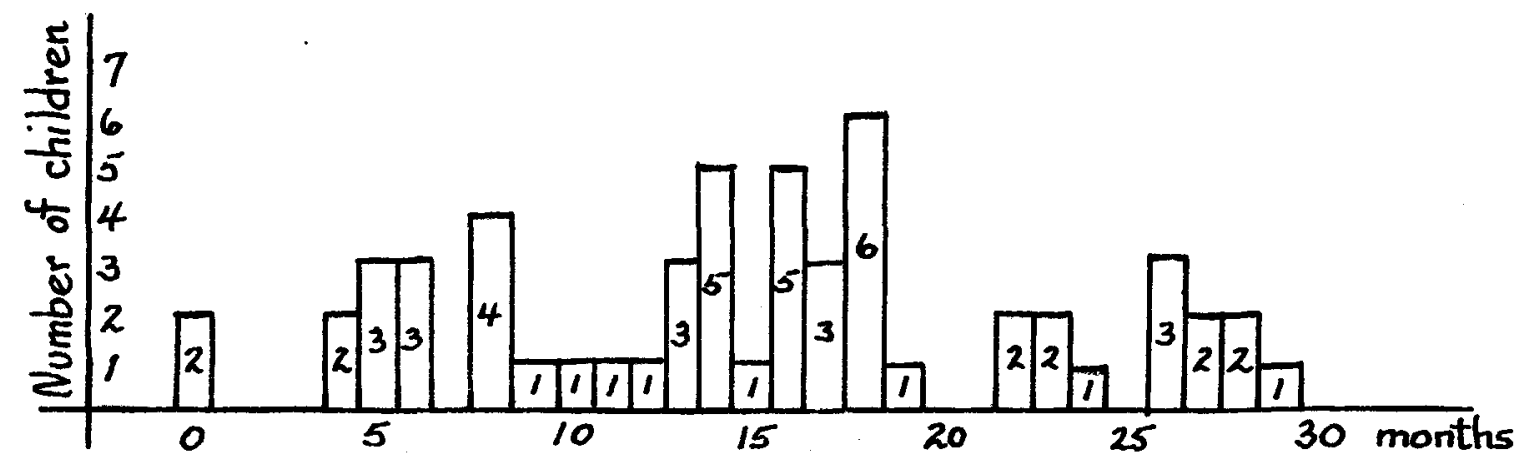


Two children made no progress in nine months; 12 made retarded progress; 41 made normal or accelerated progress; five made from 27 to 29 months in 9 months, (three years in one year).

\section{FIGURE IV}

READING PROGRESS IN MONTHS MADE BY 29 CHILDREN WHO SPENT 18 MONTHS IN THE OPPORTUNITY CLASS

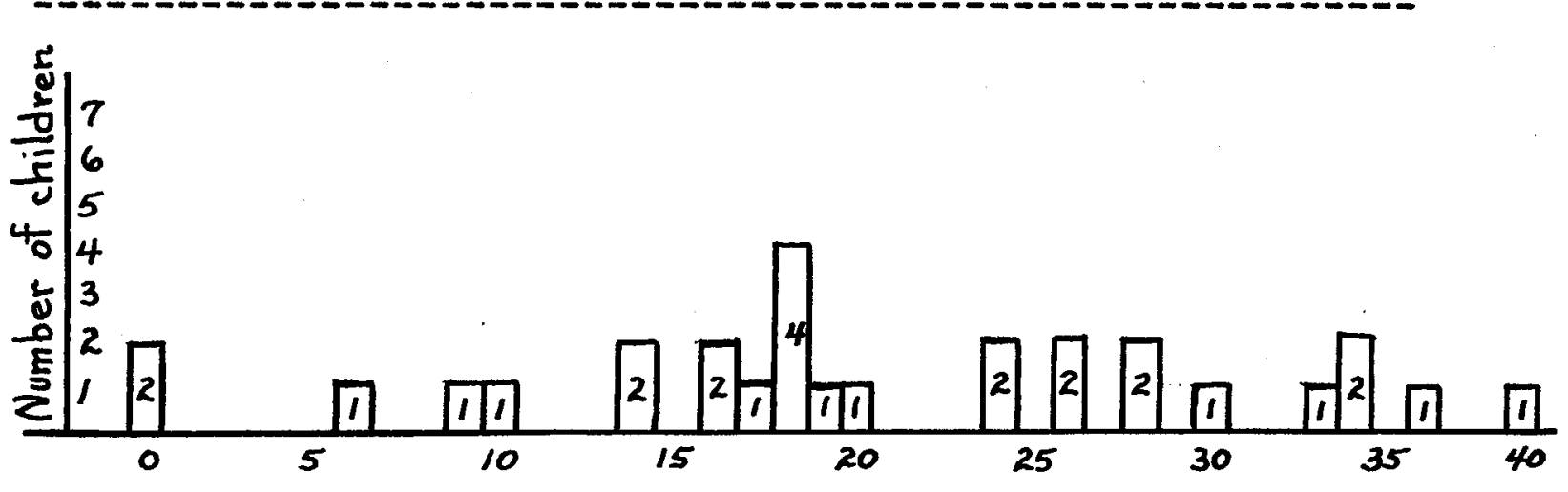

Two of this group did not learn to read and were transfered to an ungraded class; eight made retarded progress; nineteen made normal or accelerated progress. 
FIGURE V

READING PROGRESS MADE IN MONTHS BY 14 GHIIDREN

WHO SPENT 27 MONTHS IN THE OPPORTUNITY CLASS

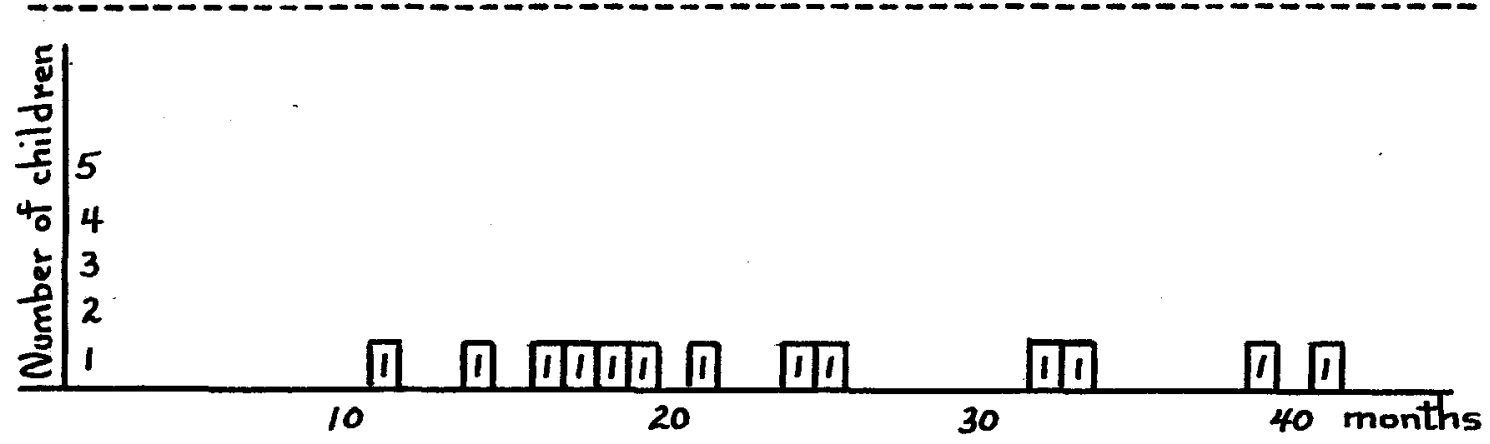

These 14 children were retarded mentally and scholastically; only four improved sufficiently to return to their normal classes. 
FIGURE VI

PERCENT OF PUPILS WHO GAINED OR IOST IN OPPORTUNITY CLASS

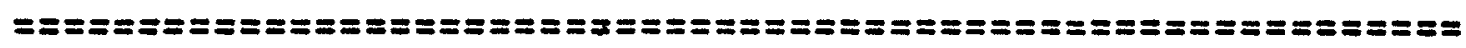

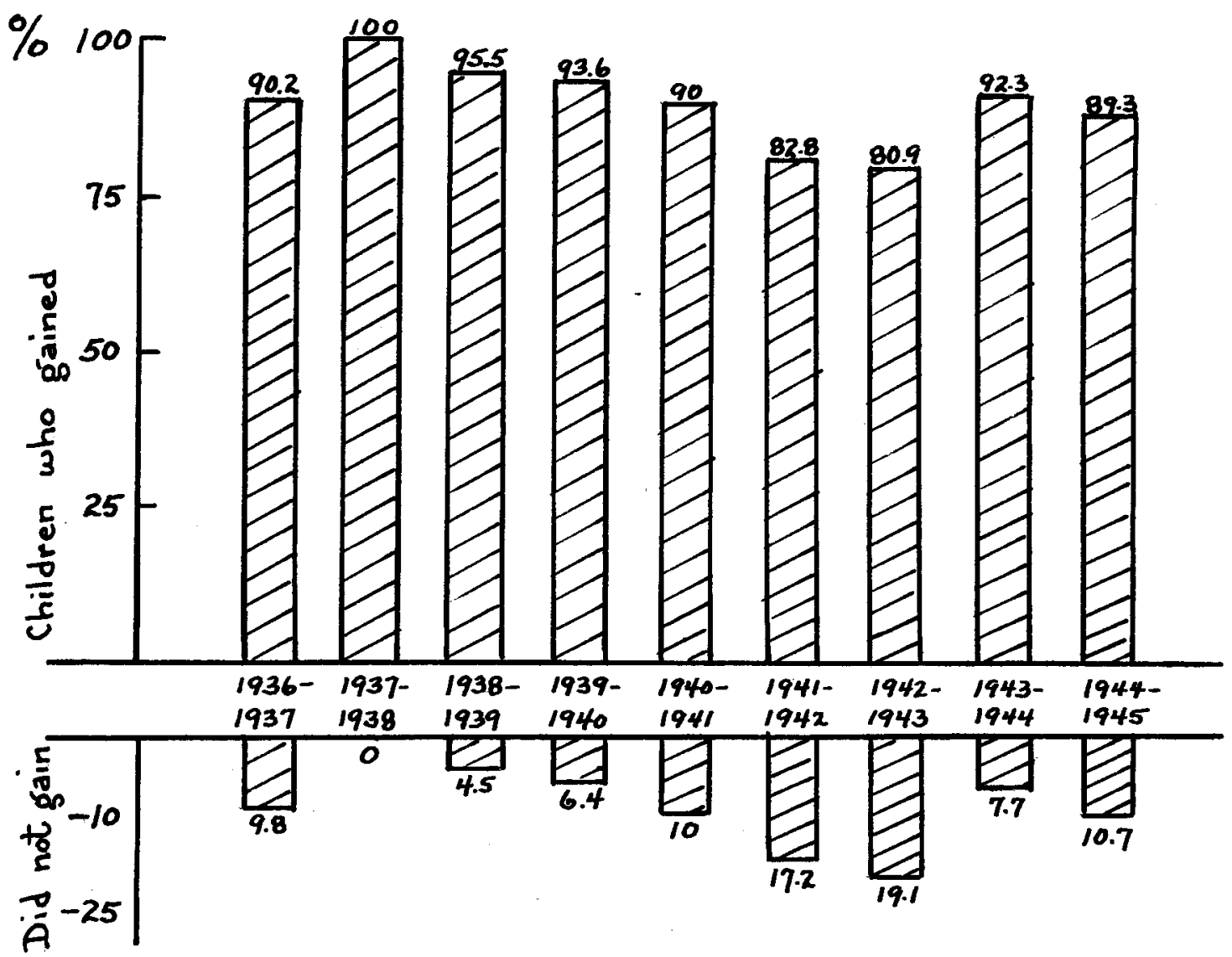

The above bar graph gives the percent each year of children who gained or lost after remedial reading instruction (1936-1945). 
TABLE I

RECORDS TAKEN FROM CHARTS KEPT IN CLASSROOM FROM 1936 TO 1945

\begin{tabular}{|c|c|c|c|c|c|c|c|c|c|}
\hline & $\begin{array}{l}1936 \\
1937\end{array}$ & $\begin{array}{l}1937 \\
1938\end{array}$ & $\begin{array}{l}1938 \\
1939\end{array}$ & $\begin{array}{l}1939 \\
1940\end{array}$ & $\begin{array}{l}1940 \\
1941\end{array}$ & $\begin{array}{l}1941 \\
1942\end{array}$ & $\begin{array}{l}1942 \\
1943\end{array}$ & $\begin{array}{l}1943 \\
1944\end{array}$ & $\begin{array}{l}1944 \\
1945\end{array}$ \\
\hline :ニニニニニニニニニニニ & Eニニニニニ & 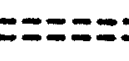 & $===ニ=:$ & $:==:=2$ & $=:==:$ & $==ニ=\Sigma:$ & $==ニ=ニ=$ & $E=:=ニ=$ & $E==:$ \\
\hline $\begin{array}{l}\text { Number } \\
\text { enrolled }\end{array}$ & 45 & 40 & 45 & 47 & 43 & 40 & 49 & 54 & 52 \\
\hline $\begin{array}{l}\text { Number } \\
\text { tested }\end{array}$ & 41 & 38 & 43 & 44 & 40 & 35 & 42 & 39 & 47 \\
\hline $\begin{array}{l}\text { Number } \\
\text { gained }\end{array}$ & 37 & 38 & 40 & 41 & 36 & 29 & 34 & 36 & 42 \\
\hline $\begin{array}{l}\text { Per cent } \\
\text { gained }\end{array}$ & 90.2 & 100 & 95.5 & 93.6 & 90. & 82.8 & $80.9^{\prime}$ & 92.3 & 89.3 \\
\hline $\begin{array}{l}\text { Number } \\
\text { did not gain }\end{array}$ & 4 & 0 & 3 & 3 & 4 & 6 & 8 & 3 & 5 \\
\hline $\begin{array}{l}\text { Per cent } \\
\text { did not gain }\end{array}$ & 9.8 & 0 & 4.5 & 6.4 & 10 & 17.2 & 19.1 & 7.7 & 10.7 \\
\hline $\begin{array}{l}\text { Number } \\
\text { returned to } \\
\text { normal class }\end{array}$ & 10 & 15 & 4 & 15 & 11 & 3 & 10 & 6 & 7 \\
\hline $\begin{array}{l}\text { Jumber } \\
\text { iransfered to } \\
\text { runior High } \\
\text { School }\end{array}$ & 3 & 0 & 5 & 0 & 1 & 1 & 0 & 0 & 0 \\
\hline
\end{tabular}

During 1936 - 1937, forty-five children were enrolled in the Opportunity Class. Forty-one were tested; thirtyseven gained ( 90.2 per cent); four did not gain $(9.8$ per cent); ten returned to normal classes; three were transferred to junior high schools. The table above gives the full record for each year from 1936 to 1945. 


\section{FIGURE VII}

ACTUAL NUMBER OF NEW CHILDREN SELECTED EACH YEAR FOR THE OPPORTUNITY CLASS

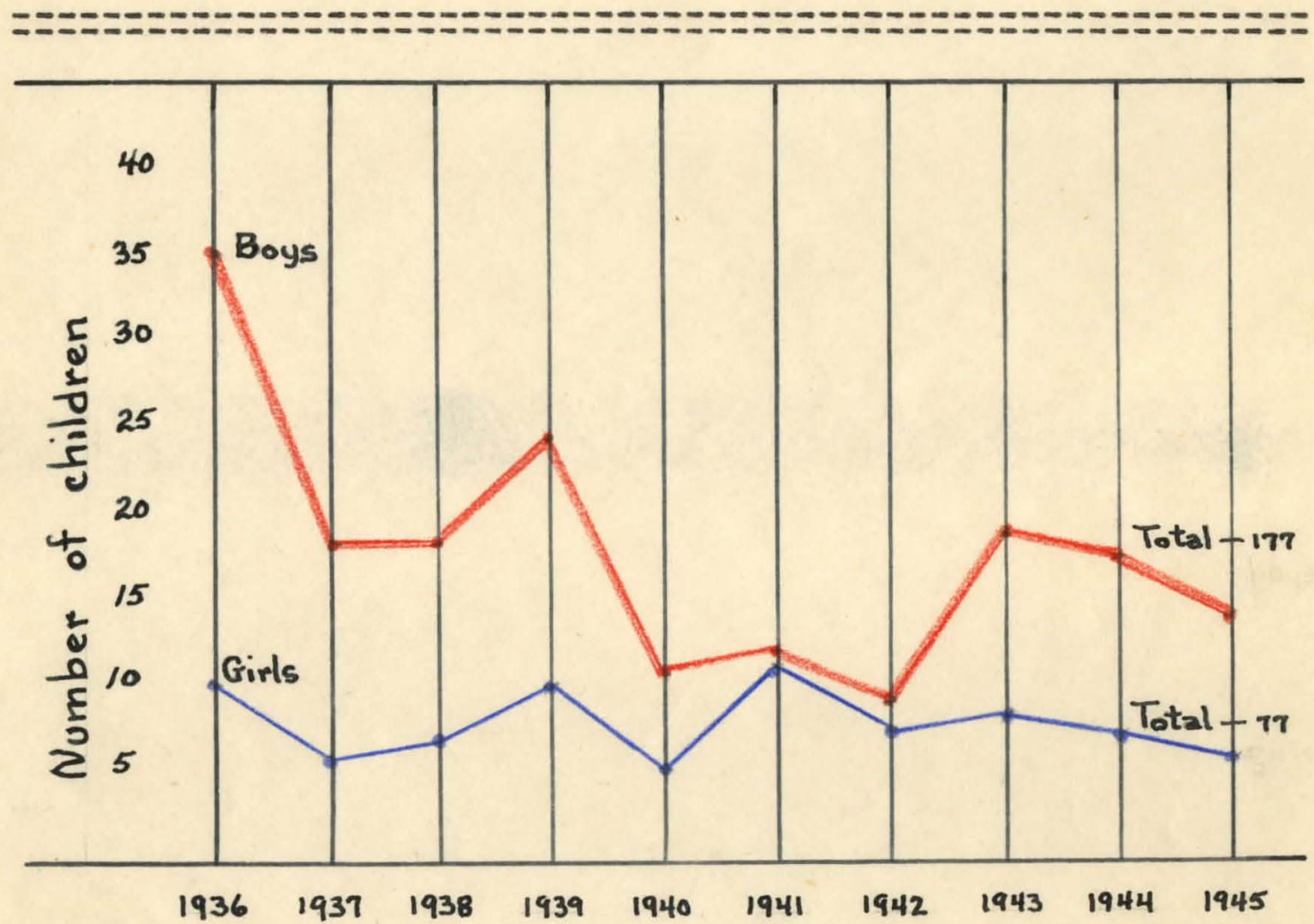

Exactly 100 more boys than girls needed remedial reading instruction. The dip in 1940, 1941, and 1942 corresponds with that of the same years on Figure VI, which shows the lowest percent of gain. When gains are low, fewer children are returned to normal classes; and so, fewer new pupils may be accomodated. Hence, fewer new children were selected during 1940, 1941, and 1942. 
TABLE II

NUMBER OF CHILDREN (BOYS AND GIRLS) SHLECTED FOR THE OPPORTUNITY CLASS, 1936 TO 1945

\begin{tabular}{|c|c|c|c|c|c|c|c|c|c|c|c|c|c|c|}
\hline & \multicolumn{2}{|c|}{ Grade } & \multicolumn{2}{|c|}{$\begin{array}{c}\text { Grade } \\
2\end{array}$} & \multicolumn{2}{|c|}{$\begin{array}{c}\text { Grade } \\
3 \\
\end{array}$} & \multicolumn{2}{|c|}{$\begin{array}{c}\text { Grade } \\
4\end{array}$} & \multicolumn{2}{|c|}{$\begin{array}{c}\text { Grade } \\
5\end{array}$} & \multicolumn{2}{|c|}{$\begin{array}{c}\text { Grade } \\
6\end{array}$} & \multicolumn{2}{|c|}{ Total } \\
\hline & $B$ & $G$ & $B$ & $G$ & $B$ & $\mathbf{G}$ & B & $G$ & $B$ & $G$ & B & $\mathbf{G}$ & $B$ & $G$ \\
\hline 1936 & 1 & & 9 & 4 & 17 & 4 & 7 & 2 & 1 & & & & 35 & 10 \\
\hline 1937 & & & 6 & 3 & 9 & 3 & 3 & & & & & & 18 & 6 \\
\hline 1938 & 4 & 1 & 3 & 2 & 7 & 4 & 4 & & & & & & 18 & 7 \\
\hline 1939 & & & 15 & & 6 & 8 & 3 & 2 & & & & & 24 & 10 \\
\hline 1940 & I & & 5 & 3 & 3 & 1 & $I$ & 1 & 2 & & & & 12 & 5 \\
\hline 1941 & I & 1 & 8 & 4 & 1 & 4 & I & 1 & 1 & & & 1 & 12 & 11 \\
\hline 1942 & & 1 & 3 & 2 & 2 & 3 & 4 & 1 & & & & & 9 & 7 \\
\hline 1943 & & 2 & 9 & 4 & 3 & & 5 & 2 & 1 & & & & 18 & 8 \\
\hline 1944 & 2 & 1 & 7 & 2 & 6 & 3 & 2 & 1 & & & & & 17 & 7 \\
\hline 1945 & & & 5 & 3 & 5 & 2 & 2 & 1 & 2 & & & & 14 & 6 \\
\hline Total & 1 & & & & 9 & & & & & $T$ & & I & & 4 \\
\hline
\end{tabular}

In October, 1936, an enrollment of 35 boys and 10 girls was selected from Grades I to $V$ of the Mary D. Hill School. of these 45 children, 12 remained in 1937; to this number 
21 boys and 7 girls were added. Each year new children are chosen to take $t$ he places of those who leave the sohool or return to the regular grades. The numbers under $B$ (boys) and $G$ (girls) indicate the actual number of new children who have entered the Opportunity Class each year from 1936 to 1945. The total number of pupils is 254, (177 boys - 77 girls).

It will be noted that most of the candidates are selected from the second and third grades. Many children show no readiness for reading until they reach these two grades. others fall behind their classmates at this time and need to be strengthened. Few children are chosen from the first grade because of mental ages or lack of reading readiness. only eight children have been taken from the fifth and sixth grades in ten years. Often they are social misfits with emotional and behavior problems because of continued fallure. They may have formed bad habits and will resist further efforts to teach them. Only those whose levels can be raised appreciably and rapidly are considered in the upper grades. 
DISTRIBUTION OF 41 CASES ACCORDING TO GRAY'S ORAL TEST SCORES, SEPTEMBER, 1945

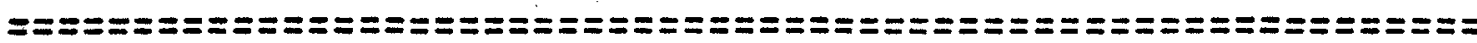

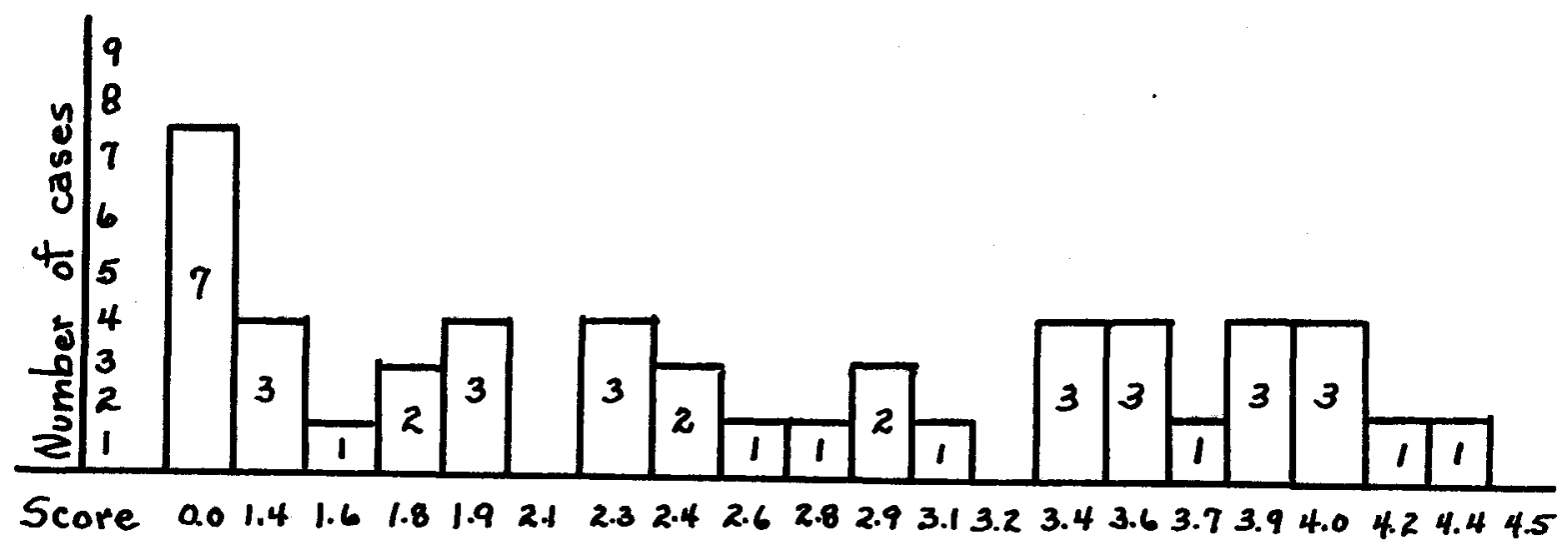

FIGURE IX

DISTRIBUTION OF 41 CASES ACCORDING TO GRAY'S ORAL TEST SCORES, JANUARY, 1946

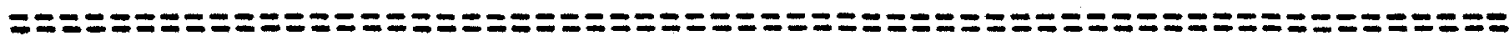

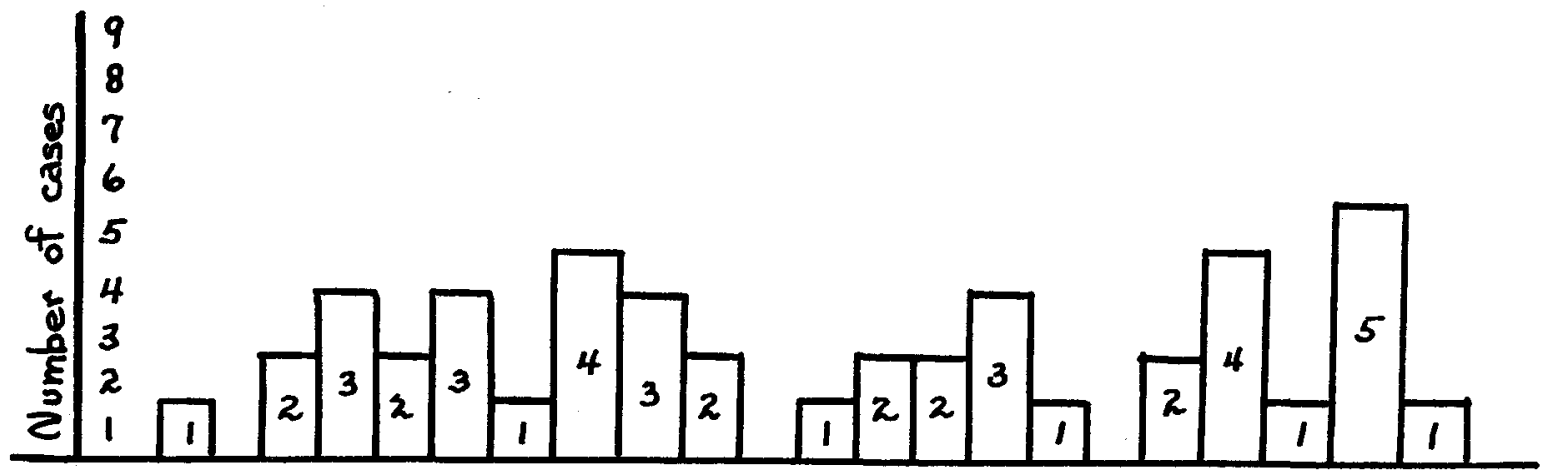

Score $0.01 .41 .6 \quad 1.81 .92 .12 .32 .42 .62 .82 .93 .13 .23 .43 .63 .73 .94 .04 .24 .64 .74 .9$

1

Gray's Oral Reading Paragraphs 


\section{FIGURE $\mathrm{X}$}

INDIVIDUAL CASE RECORDS FOR FIVE MONTHS FROM SEPTEMBER, 1945, TO JANUARY, 1946, SHOWING GAINS AND LOSSES ACCORDING TO GATES ORAL READING PARAGRAPHS.

\section{September 1945 Scores}

January 1946 Scores

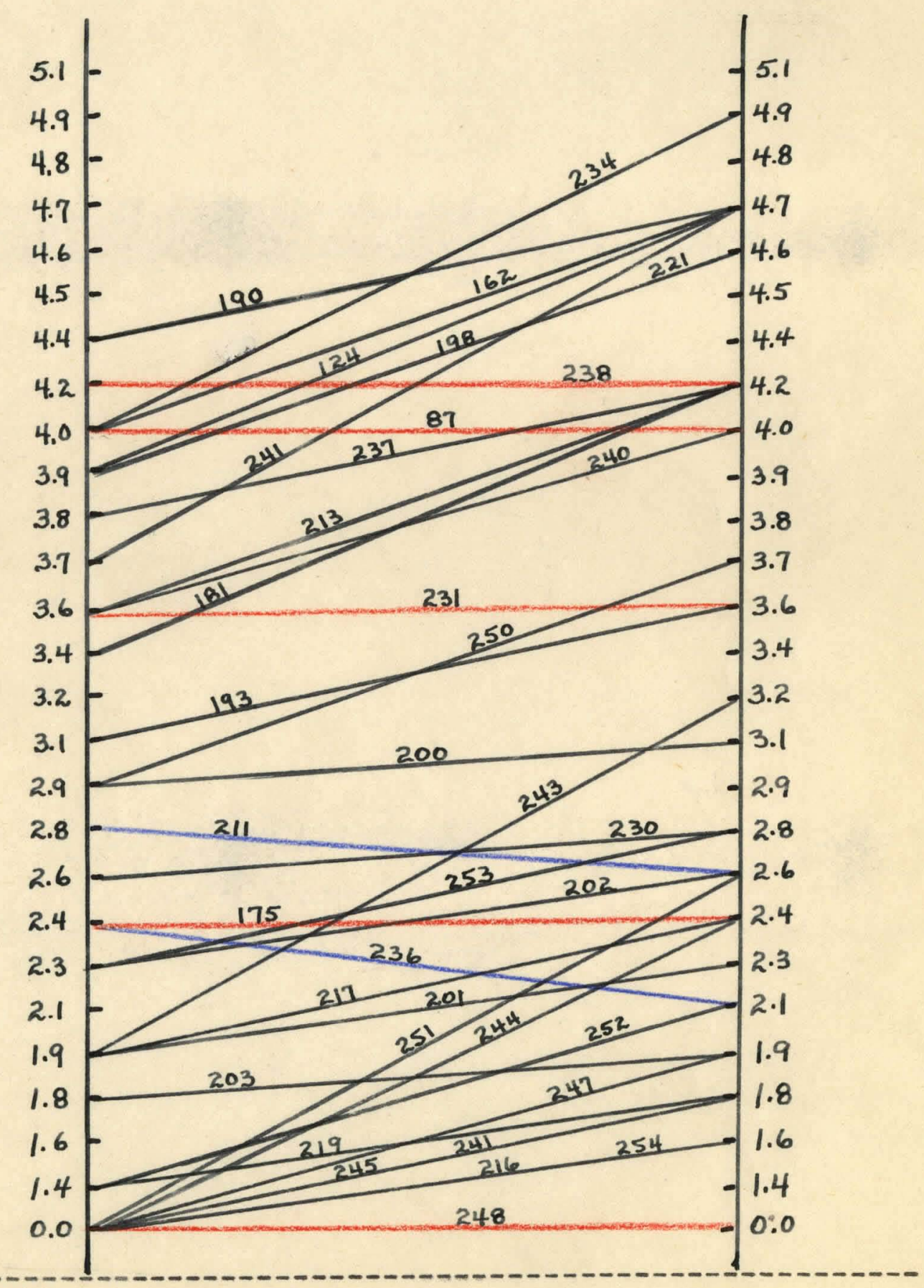


Black lines indicate individual case scores for children who gained in reading, (months).

Red lines indicate no reading gain.

Blue line indicates reading loss of three months.

The number on the lines are those used throughout this study to designate the reading cases and consequently are not consecutive here.

Case 238 made no gain. Illness in the home and frequent trips out of town may account for this.

Personal illness which may cause permanent withdrawal from school may account for no gain for Case 87.

A decided need for glasses probably caused the lack of gain for Case 231 who gained 26 months the previous year. She will be given glasses next month.

Case 175 has reached his achievement according to his scores over a period of four and a half years during which time he has gained only 14 months. In the last year and a half there has been no gain.

Cases 211 and 248 are truancy cases. Case 236 is a boy with low mentality, but there is no explanation for his loss of three months. 


\section{FIGURE XI}

CHRONOLOGICAL AGE DISTRIBUTION OF 41 CASES, SEPTEMBER, 1945

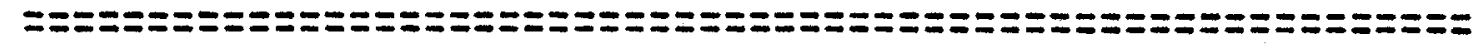

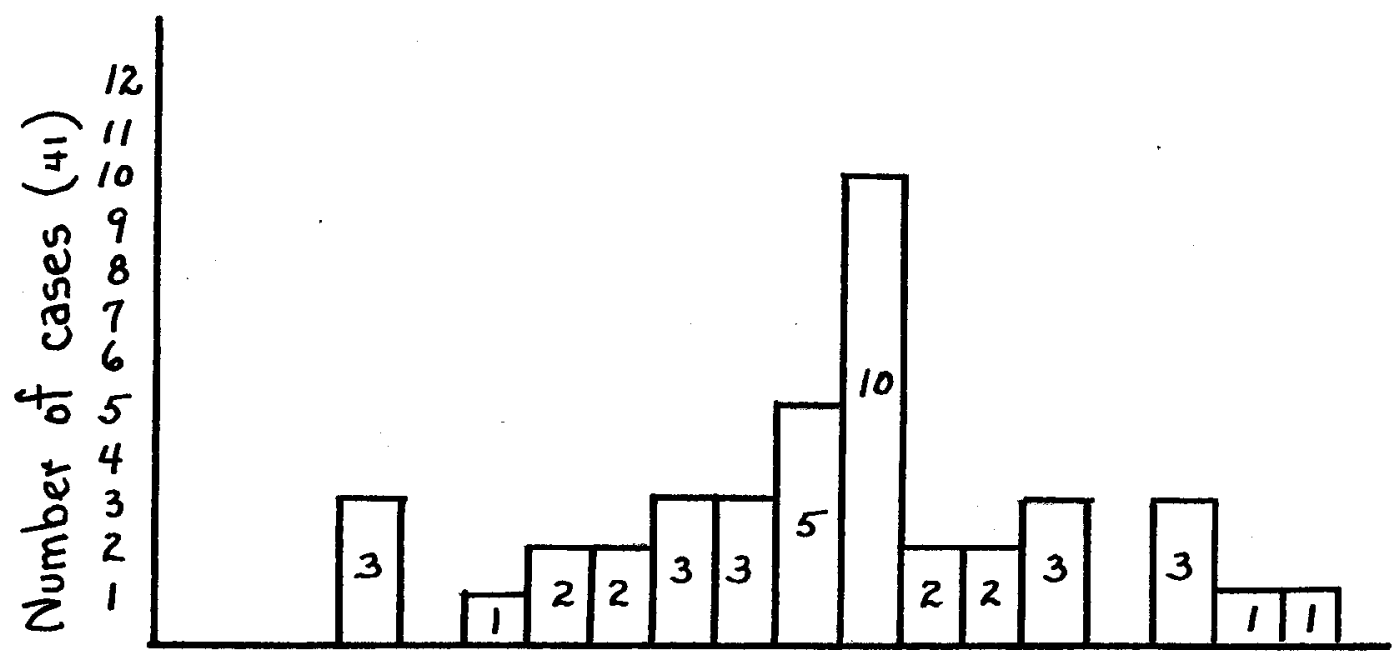

Shronological age $7 \quad 7 \frac{1}{2} 8 \quad 8 \frac{1}{2} \quad 9 \quad 9 \frac{1}{2} \quad 10 \quad 10^{\prime} \frac{1}{2} 11 \quad 11 \frac{1}{2} 12 \quad 12 \frac{1}{2} \quad 13 \quad 13 \frac{1}{2} 14 \quad 14 \frac{1}{2} 15$ 


\section{FIGURE XII}

MENTAL AGE DISTRIBUTION OF 41 CASES, SEPTEMBER, 1945

I

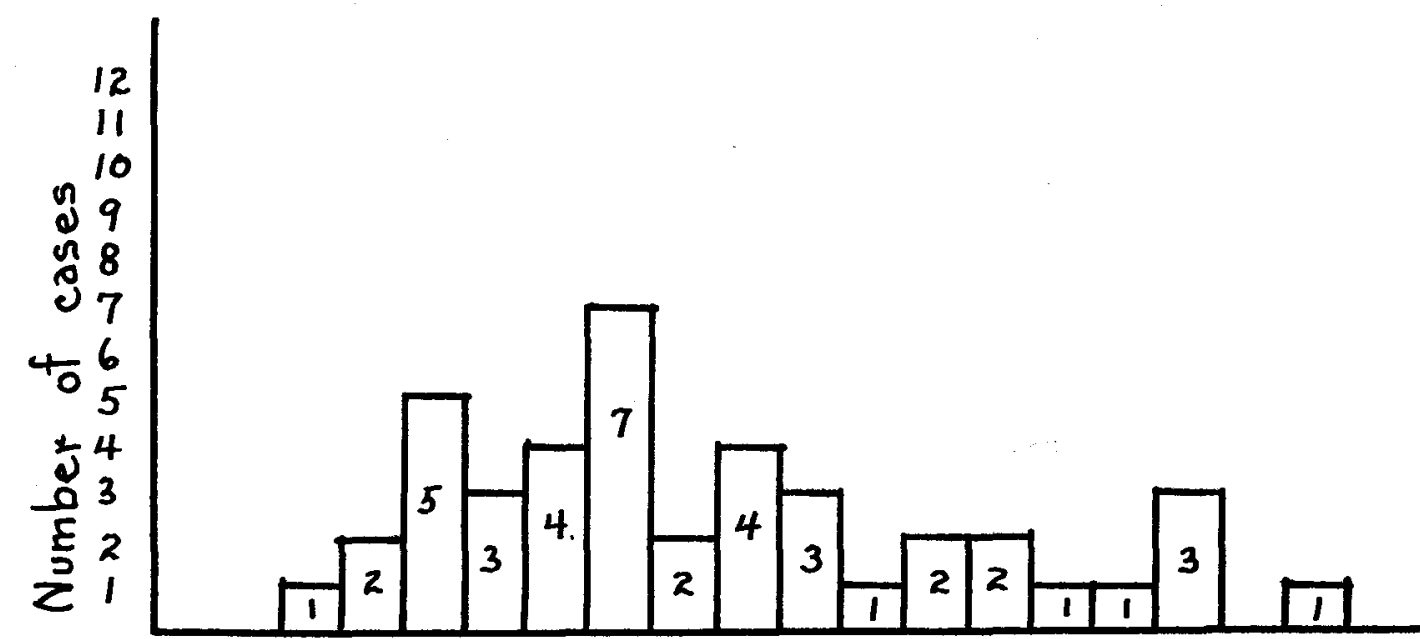

Mental age $6 \quad 6 \frac{1}{2} 7 \quad 7 \frac{1}{2} 8$ 8 $8 \frac{1}{2} 99 \frac{1}{2} 10 \quad 10^{\prime} 11 \quad 11 \frac{1}{2} 1212 \frac{1}{2} 1313 \frac{1}{2} 14$

Mental age results obtained in group testing.

Mental age median - 7 years.

Chronological age median - $11 \frac{1}{2}$ years.

\section{2}

Otis Quick-Scoring Mental Ability Tests - Alpha Test Form A - Grades 1 to 4 (Verbal and Nonverbal) Arthur S. Otis, 1936. 


\section{FIGURE XIII}

ACTUAI GRADE - PLACEMENT DISTRIBUTION OF 41 CASES

FROM SEPTEMBER, 1945 TO JANUARY, 1946

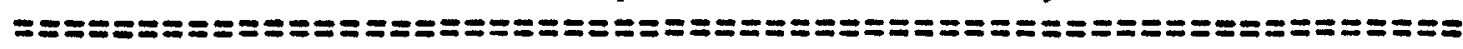

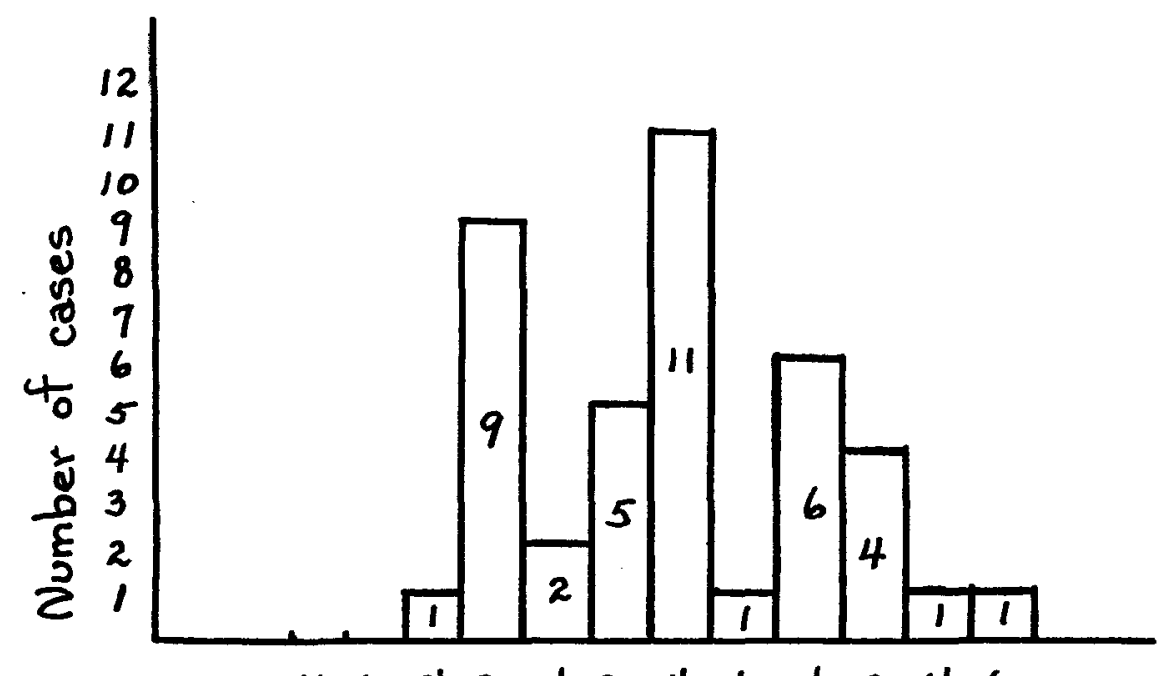

Ib la $2 b$ Za $3 b$ a $4 b$ 4a $5 b 5 a 6 b 6 a$

The 41 cases shown on the figure above are drawn from Class $2 \mathrm{~B}$ through $6 \mathrm{~A}$. 
FIGURE XIV

READING GRADE - PLACEMENT DISTRIBUTION OF 41 CASES TESTED IN SHPTEMBER, 1945

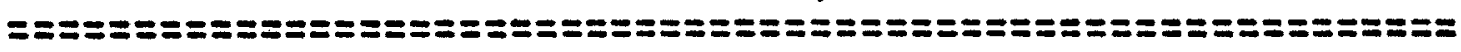

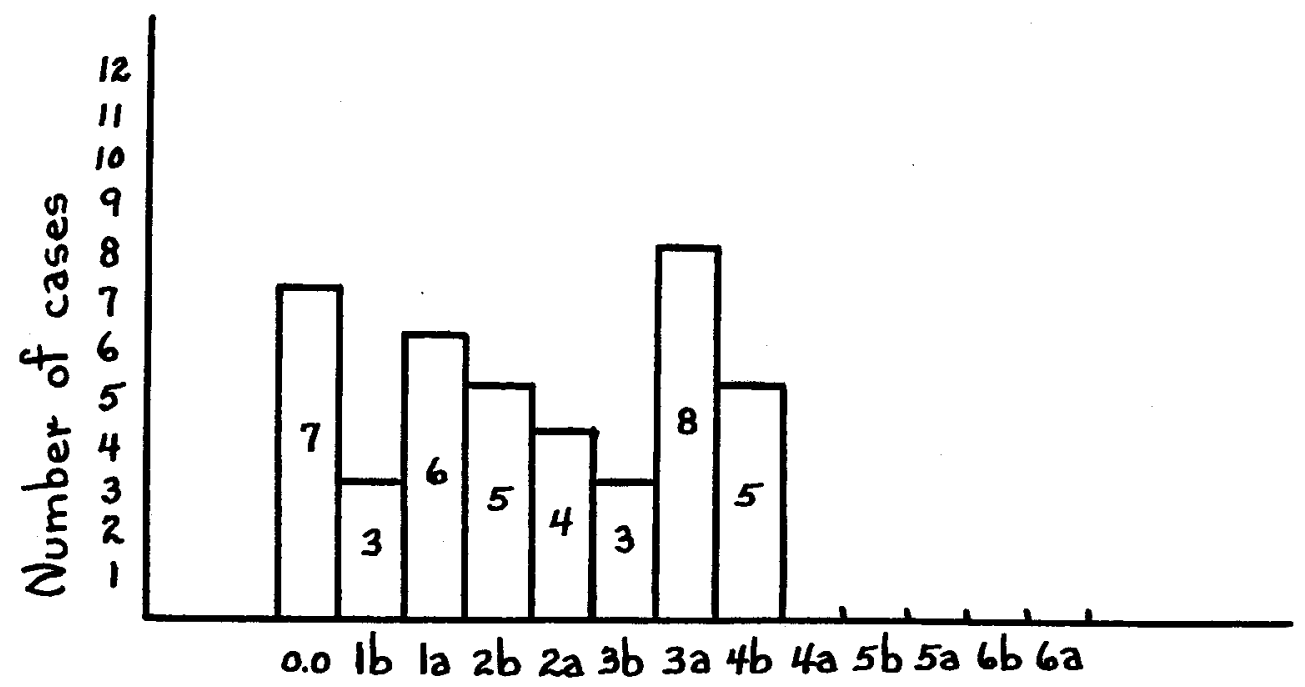

The same 41 cases on Figure XIII from $2 B$ through $6 \mathrm{~A}$ show reading scores from $0 . \theta$ only through $4 \mathrm{~B}$. 
READING GRADE - PLACEMENT DISTRIBUTION OF 41 CASES TESTED

IN J JNUARY, 1946

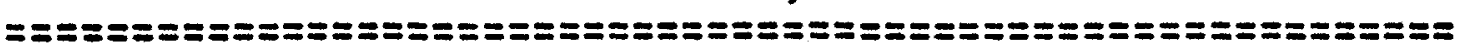

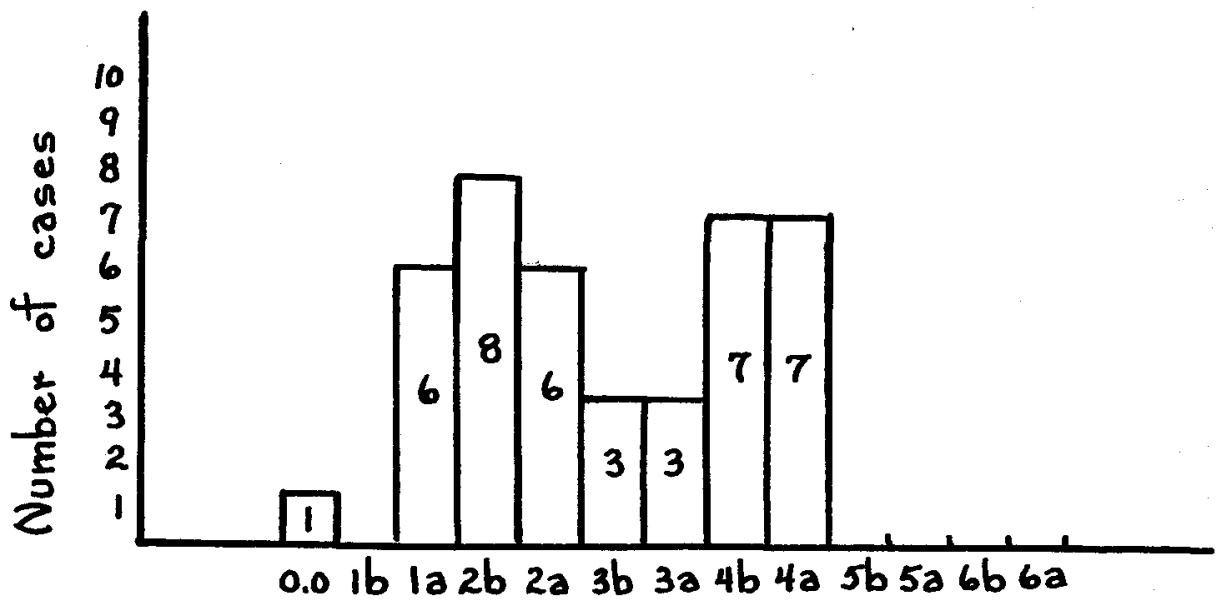

The morement to the right on this figure compared with Figure XIV indicates a general improvement in reading scores. FIGURE XVI

AGTUAL GRADE - PLACENENT DISTRIBUTION OF 41 CASES, JANUARY, 1946

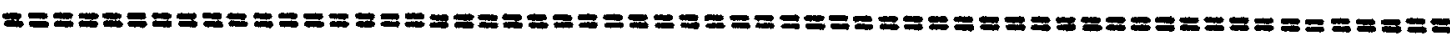

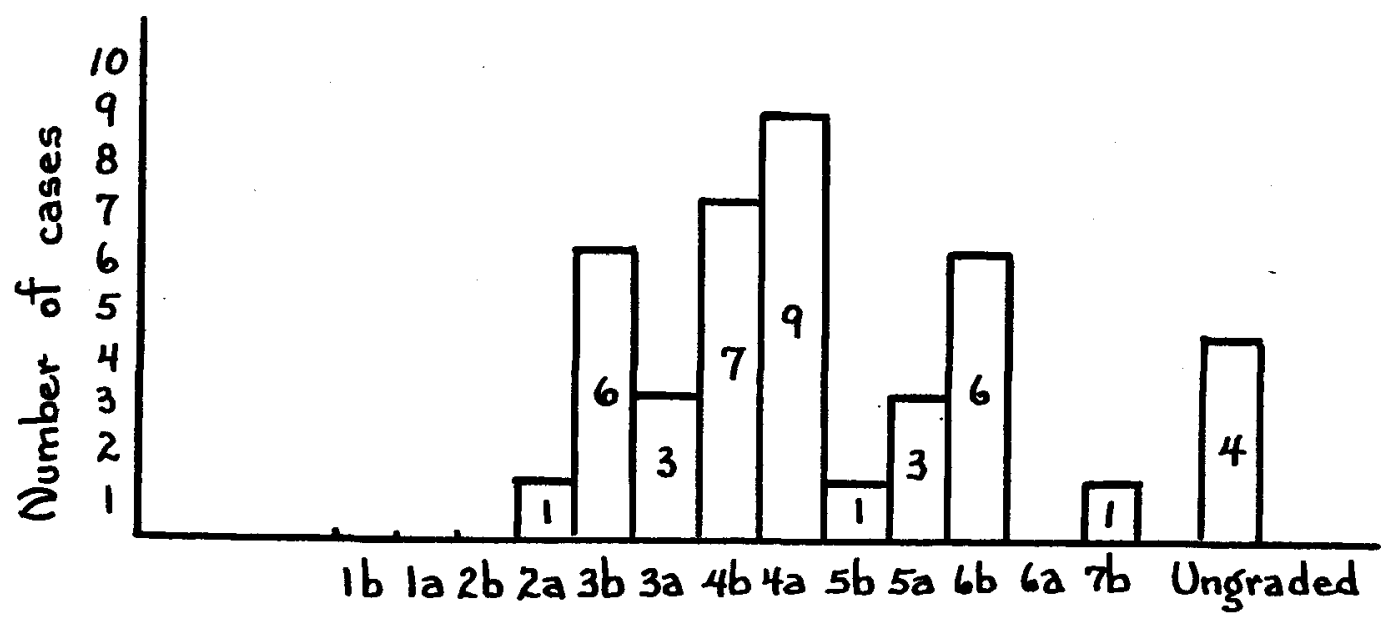




\section{TABLE III}

COMPARISON OF FIVE READING GROUPS IN THE OPPORTUNITY CLASS COACHED FROH SEPTEMBIR, 1945 TO JANUARY, 1946

\begin{tabular}{|c|c|c|c|c|c|}
\hline Geøup number & $I$ & II & III & $I V$ & $\mathbf{V}$ \\
\hline Number in group & 9 & 10 & 7 & 7 & 8 \\
\hline Average mental age & $8-9$ & $8-6$ & $7-11$ & $9-11$ & $11-9$ \\
\hline Average age & $11-6$ & $10-1$ & $11-7$ & $11-6$ & $11-9$ \\
\hline Average Sept. score & 2.6 & 1.5 & 0.2 & 3.5 & 4.0 \\
\hline Average gain in months & 6 & 9 & 7 & 6 & 6 \\
\hline
\end{tabular}

From the evidence presented above it may be concluded that the largest gains are made in the lowest groups (II and III). This is due, probably, to the fact that the teacher gave more intensive remedial instruction for longer periods and was able to correct many serious faults and disabilities.

The data for the most part indicate rapid growth in reading ability during the first year except in cases of extremely low mentality. 
TABLE IV

RANGE OF GAIN IN MONTHS DURING THE TRAINING PERIOD FROM SEPTEMBER, 1945 TO JANUARY, 1946

\begin{tabular}{|c|c|c|c|c|c|}
\hline Group Number & $I$ & II & III & IV & $\mathrm{V}$ \\
\hline Lowest gain & -2 & -3 & 0 & 0 & $\underline{0}$ \\
\hline Median gain & 4.5 & 6 & 6 & 5 & 7 \\
\hline Highest gain & 13 & 16 & 9 & 10 & 9 \\
\hline Average gain & 6 & 9 & 7 & 6 & 6 \\
\hline
\end{tabular}

According to the Gates Oral Reading Paragraphs, 5 children of the 41 in the Opportunity Class made no gains, one child lost two months (-2 in Figure $X)$ and one lost three months ( -3 in Figure $X$ ). Of those who made no gain three are of inferior mentality, one has an eye difficulty, and one is a normal boy who gained eight months last term. The two children who lost are mentally slow and need more drill. The remaining 34 in the five groups gained from one month to sixteen months in the five month's training period. 


\section{TABLE V}

NUMBER OF CASES MAKING ACCELERATED, NORMAL AND RETARDED PROGRESS OR NO PROGRESS FROM SEPTEVIBER, 1945 TO JANUARY, 1946

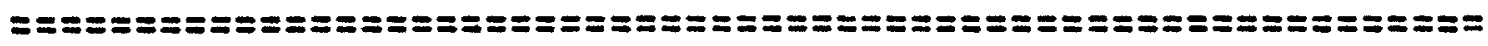
Number of cases making accelerated progress in reading 16 Number of cases making normal progress 8 Number of cases making retarded progress 11 Number of cases making no progress 6 Total 41

Accelerated progress in reading means more than one month's progress for one month's training. (See Case 241 on Figure $X)$. With continued renedial instruction the children who show accelerated progress usually reach the level of achievement desired and return to their normal groups.

Normal progress means a month's progress for a month's training. (See Case 193 on Figure X).

Retarded progress means less than a month's progress for a month's training. (See Case 203 on Figure $X$ ).

No progress means that the reading test score remains the same or drops lower after five month's training. (See Case 175 or Case 236 on Figure $X$ ).

The cases who failed to make normal progress consist of (1) children who are behavior problems or personality problems, (2) children whose attendance is irregualr, (3) children who are of inferior intelligence. 
CHAPTER V

THE EVALUATION 


\section{CHAPTER V}

THE EVALUATION

\section{Introduction.}

In preparing this chapter it was decided that the evaluation of the class from as many points of view as possible should make an interesting study. Letters were written to people who knew the Opportunity class - to seven former pupils and fifteen parents with whom the writer has maintained personal contacts over a period of years, to eleven teachers, one principal, two school supervisors, one research assistant, and two school superintendents. All letters were answered except one written to a former German refugee mother, who has recently become naturalized as an American citizen. Perhaps she has been too busy studying for her citizenship examination or was hesitant because of her feeble command of written English.

The writer is most appreciative of the thoughtful consideration and the time given by these people whose statements and letters are found on the following pages. Although permission was granted by most people to use their names, children are referred to by initials or case numbers. The statements are arranged in groups in the following order:

1. The writer's opinion of the value of her class. 
2. The opinions of the administrative group.

3. The Mary D. Hill School group.

4. The parents group.

5. The pupils' group.

The Value of the opportunity class to the Child.

In the opinion of the writer, the teacher of remedial reading in the opportunity Class, the importance of the class lies primarily in its value to the children who, because they cannot read, develop a bewildering assortment of maladjustments,- insecurity, inferiority, fears, unsocial traits that lead to truancy, lying, stealing, and other forms of delinquency. They see their brothers and sisters pass them by as they progress through school. They are left behind, a nuisance to their teachers and objects of shame to their families.

A problem which faces every teacher as the end of the semester approaches is, "To promote or not to promote?" Shall promotions be juaged on the basis of chronological age or schievement? If all children are promoted, there will be a range of reading ability in most grades from non-readers to those who may test one or two grades above the normal class level. Most teachers cannot handle such a spread of reading ability and those on the low-scoring end of the range are neglected or ignored. On the other hand, if non-readers are retained or demoted, there develops 
the undesirable situation of having older and bigger children who do not fit in the class.

If there is an Opportunity Class into which these children may be placed, the problem of non-promotion is eliminated. They move from group to group rather than from grade to grade and are placed where they can progress best.

The atmosphere and the influence of an 0pportunity Class help to develop a feeling of security between these children and tineir teachers and other children, help to relieve embarrassment, to make them feel that they have nothing of which they heed be ashamed, that the teacher has faith in them, and believes they can learn to read, and that it is fun to read. An altered program is planned for these slow-learners, one that is free of strain and disappointing failure, one which provides more time to acquire skills in groups where they can excell, and ample time for games and recreation with children their own age.

There have always been conflicting opinions among educators concerning the value of teaching academic subjects to children of lower mentality. Some feel that the time and effort are wasted because these children are not capable of using what they have laboriously learned, and maintain that this knowledge places them at a disadvantage because to all outward appearances they have had an education. others feel that the satisfaction derived from reading 
and writing as much as they can comprehend justifies the efforts of teaching and learning. The writer believes that no effort is wasted if these children learn anything at all. Even the feeblest mentality should be developed to its fullest ability.

In a coaching situation the teacher has an opportunity to study all of these problems. Often the so-called mental defectives are found to be victims of faulty diagnosis; when remedial work is given, the progress made frequently proves them to be individuals of normal or low normal intelligence and thoroughly worthy and deserving of time and attention to their needs.

The teacher has her attention called to problems of personality and the adjustment of unstable emotional characteristics. She is more concerned with these aspects and the relationship between the two developments than with achievement. She has an opporunity to study and attempt to adjust the very sensitive and excitable child, the timid, the insecure, the resentful, explosive child, the placid, dreamy one, lost or confused. She is in the most favorable position, if she understands the personality of her retarded children, to help them to growth and security. With no promotions or demotions, they may remain with her term after term, thus permitting more thorough knowledge of the child's problems on the part of the teacher. 
The Value of the opportunity class to the Mary D. Hill Sohool.

From the majority of investigations of school populations, it has been estimated that "about 60 to 75 children in each school of five hundred children should probably recelve remedial instruction in reading. " ${ }^{101}$ In the Mary D. Hill school the proportion is probably greater because 102 of the factors contributing to retardation in reading.

Each grade in the Mary D. Hill School above the second has a fair-sized group of children sufficiently retarded in reading to need remedial work. Because of the range in retardation it is not possible for the regular classroom teacher to teach them in a group nor does she have the time to give them individual attention. The Opportunity Class is this term relieving the $3 A 4 B$ teacher of twelve out of a class of 35. They range from 0.0 level to 2.8 (2A). Thus she can devote her time to more extensive reading activities with her brighter pupils. When children are placed on the roll of the Opportunity Class, the regular teacher is also relieved of the responsibility of non-promotion of these children. By the time they reach the fifth or sixth grade most of them have overcome their reading difficulties or have improved sufficiently to carry on in a regular grade. 101 Marion Monroe and Bertie Backus, op.cit.,p.3. 102

See Introduction, p.9. 
Thus the Opportunity Class "cures retardation" 103 in the Hill School.

Below the second grade retardation is often prevented if children are brought to the attention of the coach teacher before they become severe problems, chiefly through long neglect. A preventive program of early diagnosis and correction will help to remedy cases which are frequently related to emotional strains and undesirable attitudes and behaviors. With the help of the teachers and the principal the Opporunity teacher selects and examines these mentally. immature children for remedial instruction and many are restored to a normal group in a short time. There is little emotional strain or tension and serious disturbances and delinquent behavior are eliminated. Thus the Opportunity Class prevents failure and the development of maladjustments in later life.

The Value of a Goach Class from an Administrative Pointof - View.

Interest, enthusiastic approval and continued cooperation from the supervisory and administrative personnel of the Louisville Public schools are show in the following statements concerning the value of Opportunity classes to the child, the teacher, the school, and to the community $\$ 03$

See Agnes Dickson's letter in this chapter. 
at large. One is led to conclude from these favorable comments that there is a definite place for coaching classes in future educational planning and that individual differences in children are being recognized for corrective training. It is to be hoped that the community will appreciate the fact that the results of a well-organized program for exceptional children are worth any additional expense connected with special education.

In the Louisville Public School Survey of 1943, it is stated, It is the distinct credit of the Louisville Public schools that there is a recognition that the needs of mentally and physically handicapped children cannot be fully met in the regular classrooms and that special provisions are made for the mentally retarded, speech defectives, the extremely hard of hearing, the partially sighted, and the crippled. In addition there are coaching classes, stressing reading primarily, for children who are academically retarded. 104

Excerpts from a letter from Dr. C. A. Rubado, Assistant Superintendent of the Louisville Public Schools, are as follows:

"The ungraded class serves two purposes. First, and most important, the classes adjust themselves to the individual pupil rather than expect the pupil to adjust to the classes. The fact that teachers in ungraded groups work with fewer children means that each child can progress at

104

Louisville Public School Sur vey, Chapter VIII, 1943, p.277. 
his own rate. Second, and I fear the one which occurs more often, the misfit, misbehaving child is removed from the regular classroom, thus making it possible for the teacher in the regular classroom to pay more attention to the normal child.

"If there is a core of reading and simple mathematics which is necessary in order that the child may take his place in society, and if the child is slow mentally, he requires more time for academic work than the normal child. "If the work with the ungraded is properly carried out, there should be a definite case study of each child to ascertain the reason for the maladjustment in order that methods dealing with each individual case may be adjusted to the cause.

"A carefully planned curriculum, well qualified teachers, and a definite case study of each individual person, should be an integral part in any school system."

Miss Mary Browning, Supervisor of Kindergarten-Primary Education has written the following statement:

Value of a Coach Class 106

The coach class furnishes a vital opportunity for slow children to get their first feeling

\section{5}

Letter from Dr. C. A. Rubado, Assistant Superintendent Louisville Public Schools, March 9, 1946. 106

Statement by Miss Mary Browning, Supervisor of Kindergarten-Primary Education, March 8,1946. 
of security and achievement. Often lost in mass teaching, they discover their real potentialities, and gain for the first time self-confidence and a genuine interest in school. Individuals of this kind need a special program that is best adapted to them and they get it in the coach class. Personalities are often transformed after entering these classes, and they become alert, courteous, cooperative children, eager and enthusiastic about learning new things each day. This is because they realize that someone takes a particular interest in them, and is giving them special help. Their basic needs of feeling success and achievement and of being loved are being cared for. The school, too, in which the class is being conducted reaps its benefits, also. The removal from regular classrooms of special cases gives the teacher additional time to spend on the enrichment of the curriculum for the other children who do not need the training. In other words, these children, are not marking time while the slower children are being drilled, and by the same token the morale of the class is heightened considerably.

The community at large reaps the greatest good in the end as cases of delinquency are often prevented because of the adjustments which are made in these classes.

\section{7}

Miss Mary May Wyman, Supervisor of Safety and Special Education, has written a similar statement. The children to whom she refers, are the special cases that she has been instrumental in placing in the opportunity class.

\section{7}

Miss Mary May Wyman, Supervisor of Safety and Special Education, Louisvilie Public Schools, March 11,1946. 
class

A coach fills a decided need in a city the size of Louisville. There are many children who for tarious reasons have failed to learn to read. These children have normal intelligence and can succeed with school work provided they master this fundamental tool subject. If these children are given an opportunity for special, intensive instruction in reading, they are able to make normal progress. Children who realize failure are discouraged. A coach situation convinces these children that someone cares and the very fact that there is a special friend working for their best interests stimulates these children to greater endeavor. These children usually reestablish desirable social attitudes.

Special help at the right time prevents many of these children from becoming behavior probdems. These children who cannot accomplish the assigned work naturally find something to do-and that something is uaually mischief.

The coach situation should be organized to care for those normal mentally but with areas in which special help is needed.

Misg Browning feels that the special program of the coach class is valuable for the adjustment of slower children who are neglected and lost in a regular classroom. Miss Wyman, however, says that "the coach situation should be organized to care for those normal mentally." The writer agrees with both supervisors who will find themselves in the two large camps of educators who for many years have differed on the question. The writer, however, feels that coaching classes are needed for both the slow-learning pupils and "those normal mentally but with areas in which special help is needed." She enjoys teaching normal children because they 
learn rapidiy and prgress to their normal classes with little loss of time. She prefers, however, to help the backward child, the insecure, the neglected slow-learner, lost in the maze of broad objectives, aims, goals, incentives, approaches, and rich curricula. elaborately planned for the normal child. She is most pleased when a mentally normal child becomes adjusted quickly, changes his personality, achieves the grade-placement of his age level; but she is delighted when a discouraged slow child with a history of repeated failures, first recognizes the fact that he can read a sentence. In his eyes is an expression of disbelief, then joy, success, relief, and great pride. He has become a person in his own estimation. His teacher rejoices with him at every small achievement, regardless of how long and costly the process is. In the opportunity Class are children of many levels of mentality grouped to work in a special program planned for those levels.

The Dividion of Curriculum and Research, formerly known as the Bureau of Research, has a capable assistant in the person of Miss Nancy T. Collins, who administers the tests and makes the recommendations for placement of "special cases" who come to the Opportunity Class from other Louisville Schools. She writes:

I would say that the Coach Class has made it posible for many children, who would otherwise have continued to experience failure,

Miss Nancy T. Collins, Assistant, Division of Curriculum and Research, Louisville Public Schools, March 20,1946 . 
to attend regular classes and mingle on equal terms with their classmates while receiving expert remedial teaching. This has enabled many of them to gain sufficient mastery of tool subjects to return to their own buildings and continue to make regular progress. In many instances it has prevented their becoming behavior problems and in some cases has corrected already existing maladjustments growing out of failure in the past.

For mildly spastic children, for those with hearing defects sufficient to make learning in a big class difficult, for children who have marked reading disabilities, for those who have moved about so erequentiy that they have had little opportunity to gain skills and for any others who can be expected to adjust nicely in regular class rooms provided they can get the help they need in mastery of reading or aritimetic, the Coach class has proved its value.

Dr. Zenos E. Scott, 109 formerly superintendent of the Louisville Public Schools until September, 1945, has written a letter in which he says:

It was my privilege to observe remedial reading as taught to a group of pupils in the Mary D. Hill School, where pupils learned rapidiy and with thoroughness.

He further states:

I heartily approve of coaching classes or (a better term) "directed study classes", where the following points are met:

1. Teacher of regular grade from which pupils come, and teacher of coaching group possess sufficient scholarship to understand the problems to be met.

Dr. Zenos E. Scott, former Superintendent, Louisville Public Schools, March 9,1946. 


\begin{abstract}
2. Teacher of regular grade and coaching teacher mutually help each other and share in the successes and failures. 3. Pupils forming such groups to be given new yet related work to that which is under the guidance of the regular teacher. 4. Standards of achievement for group to be kept uniformly high in order that there be zest for both pupils and teachers.
\end{abstract}

Evaluation of the Opportunity Class by on-the-Spot Workers. The teachers and the principal of the Mary D. Hill School in response to a written request concerning their opinions of the value of the opportunity Class, have been most generous and encouraging in their interesting and intelligent answers. In the main, they consider the class valuable to themselves personally as it relieves them of the burden and responsibility of working with reading disability cases and undesirable overage problems. They realize that they cannot handle successfully their classes of normal children if they must be responsible for the progress of backward pupils who have been promoted according to age, height, and weight to be classed with others near their own age, height and weight. They also appreciate the extra time which they can devote to the bright children, in that the Opportunity Class does away with the third group.

The writer is greatly indebted to the faculty of the Hill School for their co-operation and splendid spirit in helping to make the opportunity class function in its en- 
deavor to adjust its many problems, both scholastic and personality. Fach teacher, in her own situation, is a coach teacher as she tries to lift the levels of these chilaren who are assigned to work with her, for a whole day or for a single period.

The writer wishes to thank these teachers for the generous help in the following statements on the evaluation of her class.

The 5A teacher writes,

"A regular teacher cannot give individual attention to a slow child and carry on the work of her entire class properly. The teacher is relieved of the burden of the slow and retarded pupils. "The Opportunity class prepares, trains and equips the children so they can carry on their work in other subjects."

Many of the teachers feel, however, that the principal value is to the child who needs to be adjusted. The IB teacher who is seldom relieved of any slowlearners because of the time required to determine the seriousness of their retardation, feels that

"it should work definitely to the advantage of the school to have such a class. . A child who is doing poor work in one subject may feel that he is a misfit, and may feel embarrassed. When hhas available a classroom where he can take extra work in his weak subject, it gives him a feeling of security. .

The 4th grade teacher feels that "the value of the coach class to the 
individual child who has reading difficulties is the all important item. "When the child finds himself in one of the reading groups of the Coach Class, he immediately has a sense of belonging to that group. He feels no social class differences since he has been correctly placed.

Since reading difficulties can best be coped with in special groups and under special guidance, a coach class is the most effective way in which to fit the school to the child."

The 2a3B teacher agrees with the $4 B$ teacher. She writes,

"The Opportunity Class eliminates the necessity of having a third group. . The slow child can work in a group at his own grade level. This will give him a feeling of confidence he would never get, working with a higher group."

The teacher of the $1 \mathrm{~A}$ grade is interested in giving a "break" to the unadjusted child for the good of the school as well as the child. She says,

"The Opportunity Class gives the laggard and the unadjusted a break. By working in this class, he is assigned to different levels in each subject which is not possible if he remains in one room all the time."

A $6 B$ teacher who formerly taught at the Mary D. Hill School writes,

"The greatest value of the opportunity class is to the child. It enables him - to progress in each subject ay his own rate of speed. - There is a chance for growth and interest in an opportunity class that would be lacking for a retarded child in a regular grade."

The 3B3A teacher of Mary D. Hill also mentions the value of the class to the school, teacher, and child. 
She states,

"It (the class) takes care of most of the children who would be real problems in a reading group. By sending them to the coach class, it gives me more time to work with my Group Two in reading, bringing up their level. These slow children would not only be problems in a school room, but in the whole school. It lowers the number of failures in the school. . If the children were forced to stay in their own class for reading, they $\mathrm{m}$ ght detelop an inferiority complex because of their slowness."

Three points are outlined by the $2 B$ teacher who writes,

"I The Child

a. Is given a chance to concentrate on work needed.

b. Progresses more rapidiy.

c. Associates with children closer to

his own age.

II The Teacher

a. Is given more time to devote to the other children.

b. Is relieved of some undesirable problems from a class.

III The School system Opprtunity Classes are one means by which the school system comes nearer to its goal of education for all."

Since the coach teacher tries to discover reading problems in their early stages or while they are still young, she seldom handles any from the sixth grade, although many sixth-graders have been helped in the lower grades and have returned to the regular classes. The $6 \mathrm{~A}$ teacher is always interested in the children whom the coach teacher has taught. She writes, 
"I have few reading problems in my class because of the Opportunity Class. By the time the poor readers reach the sixth grade, their reading level has been brought up to the point where they can read as a group. Because of this, I am able to give more time and attention to other scholastic problems that arise."

The principal of the Mary D. Hill School, Miss Agnes Dickson, has closely watched the development of the class from a group of four over-grown neighborhood boys to a class whose enrollment is city-wide and whose reputation brings many requests from other schools desiring admittance for their reading problems and personality cases.

Excerpts from her letter evaluating the class follow:

"The class cures retardation and prevents retardation. . . The class handles all reading problems in the school. Many are lifted to their level and return to their normal classes, going successfully to Junior High School. . . The procedure lifts the burden of coaching from the teachers in the building.

Children are happier when working at a level of of reading they can comprehend. They get a feeling of satisfaction. . . The attendance in this class is city-wide. . Candidates for the class are chosen from all schools . . It is a definite money-saver for the Board of Education, as grade repeating as checked."

As has been stated before, there is a difference of opinion among teachers as to the value of trying to teach academic subjects to mentally slow children. One or two of the Hill School teachers feel that the extra time spent with them could be more profitably used with more intelligent 
children, that the slow child will make little use of what he learns because of his feeble comprehension, and that the vocational subjects which will be of great help to him in later life, should take the place of the Three $R^{\prime} s$.

The 5B teacher thinks that "children who are too low, should not be placed in your type of class. Probably I do not know how much your low children are brought up beause of not knowing them in lower grades." She feels "that intelligent children lost along the line could catch up in a class where mechanics are taught which will aid them in regular class rooms."

other educators, however, are in favor of teaching even mentally defective children as much as they are able to learn concerning basic school subjects.

Miss Dickson says, "Every child, regardless of his mentality, should be educated to the extent of his ability. I believe that the mentality slow child should be taught to use his hands, to train himself for some mechanical line of work. But he should also be given as much instruction in formal school subjects as he is able to comprehend."

\section{Letters From Parents.}

When parents suddenly realize that their children are failing in school, they appeal to the school authorities or demand that something be done. After conferences are held with teachers, principals and supervisors, various adjust- 
ments are made to suit the individual cases.

The following statements have been made by mothers of children who have been transfered to the opportunity Class for special training during the years from 1936 to 1945. While all have praise and appreciation for the school and the class, and note changes in their children, such as renewed interest in school, actual improvement in school work, and continued progress in higher education, one mother sums up the general reaction in the following words, "When I made the change in schools and sent my son down there, it was the wisest move I ever made, as I do believe it was the turning point in his life."

Since all of the letters cannot be used, onily a few excerpts about typical cases have been selected.

M. D.'s mother whose four older daughters had been so successful in school, was frantic over he son's lack of achievement. She says,
M.D. was afraid of everything and every- body. In his first two years at school he gained nothing and was ridiculed by his classmates because of his backwardness. He was most unhappy and thought himself 'too dumb to learn'. "He was transfered to the Opportunity Class of the Mary D. Hill School. From the first, he seemed to regain his self- confidence because he was handled prop- erly by the teachers."

When M. S. entered the Mary D. Hill School he was suffering from an inferiority complex and had a reputation as being 
"dull, slow, and lacking." He hated school and was in the unfortunate position of having an older brother who never gave his parents any trouble and who "was always eager to get to school and enjoyed all of its activities." A year later his mother writes,

"We can never give enough thanks to Miss Wyman for suggesting that we put Marvin in the Mary D. Hill School. . He has been in the Opportunity Class one year now. Whatever tactics are used in the Opportunity Class certainly worked with our child. He is antirely different boy in his attitude at home, toward school and toward life in general. He has not only improved in his social ability but in his reading, writing and health habits.

One mother describes her son as

"a perfectly normal, healthy child in every way who did not seem able to learn to read by the method taught in his school. He, too, was becoming a personality problem changing from a sunny, happy child, to a sullen and unruly one."

She further writes,

"It was decided to put M.D. in the Opportunity Class at Mary D. Hill School. The next two and one half years were happy, constructive ones. He slowly, but surely made progress under the teaching used. The bad habits he had been acquiring were kindly, but firmly changed. In the first few weeks he told us he did not know school could be such a happy place. He has gone to Junior High School, then Senior High School, quite able to do his work."

F. C. was another personality problem whose continued failure in school and inability to keep up with his friends and classmates had made him feel inferior. His show-off 
attitude and swaggering insolence "were neither socially acceptable nor educationally effective." 110

His mother writes,

"When my son entered the Mary D. Hill
Opportunity class he was twelve years
old and had an above normal I.Q.;
never-the-less he could not read other
than an easy second grade book. When
he had been in the class for nine
months he advanced three years in
reading ability. Due to his previous
failures in school he had developed an
inferior complex toward his school work.
This advancement in reading ability was
the fundamental thing which enabled him
to overcome this inferiority complex."

Mrs. ${ }^{3}$. the mother of four very intelligent children, writes the following letter about her second child who has made a good record overseas in the United States Marines, and who expects to enter the speed Scientific school of the University of Louisville.

She writes,

"I feel that F. B. was given a foundation

in reading when he was in the coach class.

- Now he enjoys reading magazines, papers, and books. I am sure this will be a satisfaction to him as long as he lives."

The following case, B. W., was one of whom the principal and Opportunity Class teacher almost despaired. He came to the class with so many bad habits, and no scholastic levels whatsoever. He was placed in the first grade and in pre-primer reading. At the end of each semester he was

110

Harry J. Baker and Bernice Leland, In Behalf of Non-Readers, p. 14. 
placed in a new situation on the same levels and at the end of two years had made almost no progress at all. After all other methods were tried, the tracing and sounding method was used and the child began to read.

His mother has written,

"I have nothing but the highest regard for you and the school in which you teach. . . When I made the change in schools and sent B. W. down there, it was the wisest move I ever made, as I do believe it was the turning point in his life. . He is progressing rapidly and is well up to the level of the fifth grade."

Many mothers are embarrassed when their children are placed in the Opportunity Classes. This is perhaps caused by the reputation which ungraded and special classes for dull children have given to them. The ohildren and mothers of the Mary D. Hill School know the Opportunity room and have seen its advantages and attractions.

One mother writes,

"I was quite embarrassed when my son was put into the opportunity Class because he was such a poor reader. But after a very short time in your care I no longer felt that way because his reading improved so much.

When he went to Nanual High School, he made the Honor Roll several times, due to your splendid training. He graduated never having failed in any subject."

In February, 1944, Case No. 243, entered the first grade at Mary D. Hill School. Until she reached the second grade, she was a most promising pupil, normal in conduct and scholastic achievement. At that time, she developed a nervous 
behavior, a dislike for books, school and teacher. At the insistance of the principal, the child was given a physical examination. During the summer a tonsillectomy and an appendectomy were performed and she returned to school rested and quiet. To speed her recovery scholastically, she was placed in the Opportunity class.

In September, 1945 she scored 1.8 on her reading test. Four months later she scored 3.2 , a gain of fourteen months. Her mother writes,

"We feel that our child's experience in your reading class has been very beneficial. Before entering the Opportunity Class she seemed afraid and uninterested. We feel she would be back in $2 B$ now had it not been for the boost you gave her. She seems courageous and wants to read."

Another child, No. 45, also had a speech defect; but her intelligence and co-ordination were normal. For some reason, she reached the third grade without learning to read. By the time she was transfered to junior high school she had been returned to a normal class, gaining six years in three years.

In a letter her mother states,

"From the beginning of your instruction we noticed a big change in her enunciation, showing your effort in the work being done on vowels and consonants. . We have had several favorable comments regarding her reading and expression which are highly commendable. She is now attending senior high school and will graduate in June. She is carrying an advanced series of courses and par- 
ticipating in the student Council where it is necessary for her to express herself repeatedly. . It is her intention after graduation to attend college and major in English.

We thank you very much for your efforts when she was in your opportunity Class, knowing that you have done her a wonderful service."

One of the most recent entrants at the Mary D. Hill School is Case 250, a little girl who has received much attention from child specialists and psychologists. Much time and money were spent on private tutors and her parents were quite concerned over her inability to keep up with children her age. Her test results placed her in various classes at $2 \mathrm{~A}, 3 \mathrm{~B}, 3 \mathrm{~A}, 4 \mathrm{~B}$ levels. (Her individual schedule is on page 26.) From September, 1945 to January, 1946, her reading gain was eight months. Her schedule this term, is infa straight $4 \mathrm{~B}$ Grade.

Her mother writes,

"My daughter first attended school in a
public school out of this state. She
then was placed in a private school.
the term previous to going to school here,
at Mary D. Hill.
We have been greatly encouraged in her
attitude toward sohool and the interest
she has taken in studying, since she has
been in the opportunity class. I can say,
without a doubt, that she has learned more
this year in school than in her total
previous attendance."

Former "Opps" Write Letters:

Seven former pupils have given personal reasons for feeling that the training they received in the opportunity 
Class was valuable to them after they left the Mary D. Hill School. Two girls, J.D. and M. J. M.a graduating seniors in a local high school. J. D. was a second-grader in 1936 making a 0.0 score on her first reading test. In 1941 she went to Junior High School with a 7.0 score. She writes,
"My experience with you in the Opportunity Class was of great value to me. Through your patience and understanding of my faults and weaknesses, I learned to read and am now in my last year of high school. Thank you for helping me to get here."

M. J. M. whose speech defect, "baby-talk", was never completely corrected, writes,

$$
\begin{aligned}
& \text { "If it had not been for your patience and } \\
& \text { interest in helping me to learn to read, } \\
& \text { it would have been difficult for me to } \\
& \text { continue my advanced studies. The phonics } \\
& \text { you taught me have been of great service } \\
& \text { to me. They have not only helped me in } \\
& \text { my reading, but also have been an aid in } \\
& \text { my pronunciation of Latin and French." }
\end{aligned}
$$

George, one of the members of the original ungraded class, when handwork played such an important part in ungraded work, won prizes and ribbons in better homes and dish garden contests.

He writes,

"When I entered the Mary D. Hill School, I was placed in the ungraded class where

I began to learn to read and spell. I also learned to use my hands. This has helped me to make a successful mechanic. I now own my own garage."

J. H., another big country boy who gained four years 
and three months in reading, from October, 1936 to May, 1937, writes,

$$
\begin{aligned}
& \text { "I'm for more opportunity classes like yours. } \\
& \text { Children learn faster in your special class } \\
& \text { because they feel more or less at home, } \\
& \text { doing interesting things that they can do, } \\
& \text { things they like to do." }
\end{aligned}
$$

A corporal in the United States Army, R. H., who had remedial reading from September, 1938 to Hay, 1940, types a very good letter from Kobe, Japan. He writes,

"The Opportunity Class is wonderful for children who cannot read. I am grateful to you, the teacher, for what you have done for me."

C. S., whose reading level was still one year retarded when he was transfered to a junior high school ungraded class, gives credit for his ability to use a printing press to a knowledge of phonics which he learned in the Opportunity Class. He says,

"of course, I keep a dictionary at my side at all times; but phonics have helped me to spell and read. I couldn't hold my job if I hadn't been in your opportunity Class."

Another boy, now in the Army, D. A. N., who was fourteen months retarded at the beginning of his training, and who gained twenty-five months in fifteen months, says,

"I always was slow in reading, but I had what you used to call a "crutch". When I was in the sixth grade, I could figure out a new word before any of the good readers could. I used phonics which they did not Know." 
THE SUMMARY 
THE SUMMARY

The Mary D. Hill Opportunity Class has had the assistance and advise of several of Louisville's educators, but it has suffered, somewhat, from changes in supervisors, lack of knowledge on special education, lack of materials; and procedures were often planned as the project went along. The program was new and untried; and mistakes, confusions, and misunderstandings were inevitable. It is impossible to evaluate the helpful and hindering features of the class; and the less tangible and highly valuable interpretations given in this report are based upon reports and judgments of interested observers.

What results may we expect from our attempts to provide for individual differences? We can help each child to feel "increasingly secure, increasingly important to group living, by participating as an individual with relation to the group 111 processes." He needs to feel safe for the future, living in an orderly world. He needs the feeling of belongingness and personal worth.

The tangible results of the reading program have been indicated on Figures I, II, III, IV, V, VI. Two hundred fifty-four children have been given remedial instruction in the ten years during which test results were kept. Only one child suffered loss on his reading score while 29 cases

\section{1}

Margaret Leckie, op.cit.,p.6. 
showed no improvement scores on the re-tests. These children either moved away without being re-tested, or before any improvement could be expected, or had difficulties too complex for analysis or improvement by the reading teacher. Two hundred twenty-four children made reading gains and 81 returned to their normal classes.

Besides improvement in reading, valuable changes in attitudes and behavior were reported by parents and teachers. Some changes noted were:

1. Improved behavior at home and at school.

2. Attitude toward teachers and school more favorable.

3. Inferiority complex disappeared.

4. Confidence restored.

5. Fear of failure removed.

6. Truancy disappeared.

7. Better marks in other subjects.

8. Speech defects improved.

9 . Dislike of reading removed.

10. Feeling of belonging noted.

These and other similar statements lead one to conclude that adjustment both in reading and school subjects and in personality is possible in the Opportunity class.

Remedial work can be carried on by the regular teacher working with her retarded pupils two or three periods a week, if a special remedial teacher is not available for each school. A teacher must be friendly and sympathetic, 
one who will adapt herself to each child's individual differences, one who will recognize the problems and plan effective treatment for the child's difficulties. of course, some teacher-training in remedial work is necessary. The principal and supervisors can provide helpful suggestions. Since each case presents a different problem, which must be carefully studied, there is no specific method for correcting reading defects. Many techniques have been successfully used. The types mentioned in this study have produced satisfactory results with a majority of the children. Some, however, cannot be returned to their regular grades because their mental ages are a number of years lower than their grade-placements.

To reduce the amount of remedial work for the regular classroom teacher, a program emphasizing preventive work in the primary grades may prove successful. Preventing retardation is less expensive than curing retardation.

Recommendations.

1. There should be a special remedial class in each school where both individual cases and small groups of slowlearners, may be given effective remedial instruction.

2. If a class for each school is not feasible, Opportunity classes could be maintained in various sections of the city as centers to which schools could send their non- 
readers who are able to "take part in all classroom activities not directly dependent upon reading." ${ }^{112}$ At present, the Mary D. Hill School Opportunity Class is the only one of its kind in the city of Louisville. Here it is possible to enroll only a small percentage of non-readers because of limited facilities and an over-crowded condition in the school.

It is true that all classes where specialized work is done with small groups or with individual children are costly, both in materials and in teacher personnel. Host elementary teachers are familiar with the general techniques of teaching reading, but are not prepared to deal with individual pupils. These teachers have to be trained; and many conferences between teachers and supervisors are necessary. Suitable materials are hard to find for slow-readers in the upper grades. Funds would be necessary for the service of consultants and experts to assist in a project of city-wide proportions.

A reading program of this type, however, would in time prove its worth and lighten its own load by correcting disabilities in their early stages and thus would eliminate costly grade-repetitions.

However great the problems and the cost, the goal of the experiment would be "a demonstration in a public

112

Grace M. Feñald, op.cit.,p.152. 
school system of methods of meeting personal and social needs of children to the end that they may live haopily and effectively in their group relationships." 113

"In school, at home, no matter where, one must never forget that the slow-learner is no less a person, no less an individual, than any other human being. His talents may be few, his promise slight, but he is none the less a member of mankind, cast in the same mold and made of the same clay. He claims equal rights with others in the regard of his fellow men, and to guidance and instruction designed to stimulate his growth to the fullest stature his powers permit. He, too, must be helped to stand on his own feet and face the world, self-reliant and unafraid, With malice towards none, with charity ofr all', must be the teacher's watchword. Any other point of view denies the faith that has made America great." 114

\footnotetext{
113 Forword. Bertie Backus in Marion Monroe, op.cit., p.XI in 114 W. B. Featherstone, op.cit., p.101.
} 
BIBLIOGRAPHY 


\section{BIBLIOGRAPHY}

\section{A. Books}

Abney, Louise and Dorothy Miniace, This Way to Better Speech, New York:World Book Company, 1940

Berkson, Isaac B., Preface to an Educational Philosophy, New York: Columbia University Press, 1940

Buswell, Guy T., An Experimental Study in the Eye-Voice Span in Reading, Educational Monograph, No.17, University of Chicago Press

Caswell, Hollis I. and Doak S. Campbell, Curriculum Development, New York: American Book Company, 1935

Dolch, E. W., The Psychology and Teaching of Reading, New York:Ginn Publishing Company, 1931

Dunklin, Howard, Prevention of Fallure in the First Grade, New York:Teachers' College, Columbia University, 1940

Featherstone, W. B., Teaching the Slow Learner, New York: Teachers' College, University of Columbia, 1941

Fernald, Grace M., Remedial Techniques in Basic School Subjects, New York:McGraw-Hill Book Company, 1943 
Gans, Roma, Guiding Children's Reading Through Experiences, New York:Teachers' College, Columbia University, 1941

Gates, Arthur I., The Improvement of Reading, New York: The Macmillan Company, 1935

Gates, Arthur and Jean Ayer, Let's Look Around, New York: The Macmillan Company, 1939

Gates, Arthur, Miriam B. Huber and Celeste C. Peardon, Jim and Judy Series, New York: The Macmillan Company, 1939

Good, Carter V., A. S. Barr and Douglas E. Scates, the Methodology of Educational Research, New York:D. Appleton Century Company, 1936

Gray, William S., Remedial Cases in Reading, Chicago: University of Chicago Press, 1922

Harris, Albert J., How to Increase Reading Ability, New York: Longmans, .1940

Hildreth, Gertrude, Learning the Three R's, Minneapolis Educational Publishers, 1936

Judd, Charles H., Reading, Its Nature and Development, $2: 4$ University of Chicago Press

Kirk, Sam A., Teaching Reading to Slow Learning Chiloren, Cambridge, hassachusetts:Riverside Press, 1940 
Monroe, Marion, Children Who Cannot Read, Chicago:The University of Chicago Press, 1932

Monroe, Marion and Bertie Backus, Remedial Reading, Boston: Houghton-Mifflin Company, 1937

Pennell, Nary F., and Alice M. Cusack, The Teaching of Reading for Better Living, Boston:Houghton-Mifflin Company, 1937

Smith, Nila B., American Reading Instruction, New York: Silver Burdett Company, 1934

Waring, Edith B., Helps to Learning, The Children's Institute, New York:The Grolier Society, 1928

Works, George A., Survey Report of the Louisville Public School System, 1943 


\section{B. Magazines}

Judd, Romie Dustin, "Psychologize Your Teaching," Kentucky School Journal, 24:3 (Nobember, 1945),22-25

Tinker, Miles A., "Remedial Methods for Non-Readers," School and Society, XI, (October, 1936), 524-26 


\section{Pamphlets}

Baker, Harry J. and Bernice Leland, In Behalf of Non-Readers, Bloomington, Illinois:Public School Publishing Company, 1934

Course of Study, Reading in the Elementary School, Louisville Public Schools, 1942

Gann, Edith, Reading Difficulty and Personality Organization, Morningside Heights, New York:King's Crown Press, 1945

Gates, Arthur I. and Miriam C. Pritchard, Teaching Reading to Slow Learning Pupils, New York: Teachers' College, Columbia University, 1942

Gray, William S., "Adjusting Reading Programs to Individuals," Conference on Reading, University of Chicago, III:52 (October, 1941)

Gray, William S., Co-Operative Efforts in Schools to Improve Reading," Conference on Reading, University of Chiacgo, IV: 56 (September, 1942)

Gray, William S., "Recent Trends in Reading," Conference on Reading, University of Chicago, 49:(November, 1939)

Gray, William S., "Summary of Investigations Relating to Reading," Conference on Reading, University of Chicago, 28: (June, 1925) 
Hildreth, Gertrude, and Josephine L. Wright, Helping

Children to Read, New York:Teachers' College, Columbia University, 1940

Monroe, Marion, Suggestions for Remedial Instruction in Reading, Chicago:Department of Public Welfare

Wright, Wendell, Reading Readiness, Bloomington, Indiana: University of Indiana, 1936

Wrightstone, J. Wayne, Determining Readiness for Reading, Board of Education of the City of New York, 6: (September, 1943) 


\section{Bulletins}

Fourth Annual Research Bulletin, Research Problems in Reading in the Elementary Schools, The Elementary English Review, (February, 1936)

Leckie, Margaret, "Provisions for Individual Differences," Teachers' Service Bulletin in Reading, 8:4 (April, 1943) McCarthy, May E., "Teaching Reading to the Slow Learner," Teacherg' Service Bulletin in Reading, 6:4 (February, 1943) 
E. Manuals

Cole, Arthur H., and Karl W. Bigelow,

A Manual of Thesis Writing, New York: John Wiley and Sons,1934

Newsom, N. William and George W. Walk, Form and Standards

for Thesis Writing, Scranton, Pennsylvania:International

Textbook Company, 1944 
F. Government Doouments

Rogers, James Fred, Speech Defects and Their Correction, Washington, D. C., United States Government Printing Office, 22 (October, 1981)

White House Conference on Special Education, "Child Care and Protection," Section III ( page 21) 
G. Newspaper Article

Marke, David Taylor (Associated Press), "Help for the Mental Left-Hander," Louisville Courier-Journal, 182:2 (October 23, 1945) 
H. Unpublished Manuscripts

Dickson, Agnes B., Report on Opportunity Class at Mary

D. Hill School, Report to Dr. J. K. Long, Assistant Superintendent of Louisville Public Schools, 1938

Sperry, Mildred E., Master's Thesis, Smith College of Social Work

Swan, E., Twe Relative Difference of Abstract Words and

Words with Meaningful Concepts, Master's Thesis, University of Idaho, 1939 
I. Tests

Gray, William S., Standardized Oral Reading Paragraphs, Bloomington, Illinois:Public School Publishing Company.

Otis, Arthur S., otis Quick-Scoring Mental Ability Tests, Alpha Tests, Grades one to Four (Verbal and Nonverbal) Chicago: World Book Company 